\section{(A) Check for updates}

Cite this: Food Funct., 2021, 12, 1020

\title{
Comprehensive in vitro antidiabetic screening of Aspalathus linearis using a target-directed screening platform and cellomics
}

\begin{abstract}
Nadine A. Pringle, (D) * Maryna van de Venter and Trevor C. Koekemoer
The antidiabetic potential of Aspalathus linearis has been investigated for over a decade, however, its characterisation remains incomplete with results scattered across numerous journals making the information difficult to compare and integrate. To explore whether any potential antidiabetic mechanisms for A. linearis have been neglected and to compare the suitability of extracts of green and "fermented" A. linearis as potential antidiabetic treatment strategies, this study utilised a comprehensive in vitro antidiabetic target-directed screening platform in combination with high content screening and analysis/cellomics. The antidiabetic screening platform consisted of 20 different screening assays that incorporated 5 well-characterised antidiabetic targets i.e. the intestine, liver, skeletal muscle, adipose tissue/obesity and pancreatic $\beta$-cells. Both the green and fermented extracts of $A$. linearis demonstrated very broad antidiabetic mechanisms as they revealed several promising activities that could be useful in combatting insulin resistance, inflammation, oxidative stress, protein glycation and pancreatic $\beta$-cell dysfunction and death with a strong tendency to attenuate postprandial hyperglycaemia and the subsequent metabolic dysfunction which arises as a result of poor glycaemic control. The green extract was more successful at combatting oxidative stress in INS-1 pancreatic $\beta$-cells and enhancing intracellular calcium levels in the absence of glucose. Conversely, the fermented extract demonstrated a greater ability to inhibit $\alpha$-glucosidase activity as well as palmitic acid-induced free fatty acid accumulation in C3A hepatocytes and differentiated L6 myotubes, however, further studies are required to clarify the potentially toxic and pro-inflammatory nature of the fermented extract.
\end{abstract}

Received 5th October 2020 Accepted 23rd December 2020 DOI: $10.1039 / \mathrm{dOfo} 02611 \mathrm{e}$

rsc.li/food-function

\section{Introduction}

The World Health Organisation has classified diabetes as one of the four priority non-communicable diseases to be targeted for action by global leaders. This is largely due to the inaccessibility of affordable treatments for diabetes in many low- and middle-income countries which results in countless complications and premature deaths, thus placing undue strain on an already overburdened healthcare system. ${ }^{1}$ Consequently, there is an urgent need for the discovery of alternative antidiabetic treatment strategies that are more affordable and easily accessible to those living in developing countries.

To date, no cure for diabetes exists and current treatment approaches are thus aimed at controlling blood glucose levels in an attempt to reduce the risk of diabetes associated complications. Despite the wide array of antidiabetic pharmacological

Department of Biochemistry and Microbiology, Nelson Mandela University, Port Elizabeth, South Africa. E-mail: s212418181@mandela.ac.za agents, most of these medications are accompanied by adverse side-effects including weight gain, severe bouts of hypoglycaemia, gastrointestinal problems and in severe cases, liver and heart failure. More importantly, these drugs remain expensive and largely inaccessible to most of those in the African population that need it. ${ }^{2}$

Medicinal plants and functional foods have emerged as a plausible strategy to improve diabetic outcome, ${ }^{2-4}$ and others however, the vast majority remain essentially undefined in terms of antidiabetic efficacy and safety. Given the substantial repertoire of African medicinal plants used to treat diabetes, ${ }^{2}$ and the excessive costs to clinically confirm therapeutic efficacy, few are likely to ever be sufficiently characterised to fully justify their inclusion into healthcare programs. The multi-factorial nature of diabetes combined with the multicomponent complexity of plant extracts create an extremely challenging task to define the true therapeutic potential of medicinal plants. In general, most studies relating to antidiabetic medicinal plants are based on a trial and error approach, in which animal models are selected based on popularity and 
availability rather than the molecular mechanism(s) simply because the precise therapeutic target is not revealed in existing traditional knowledge. Consequently our understanding of the antidiabetic properties of these plants remain at best incomplete and highly fragmented.

Recent technological advancements in cell culture techniques which allow high throughput screening and improved predictive capacity, through the advent of cellomics, ${ }^{5}$ raises the possibility for an alternative approach in which targetdirected in vitro screening forms the basis to identify the full domain of antidiabetic mechanisms prior to animal and clinical studies. No doubt the accuracy of such an approach is highly dependent on the comprehensiveness of the screening platform to ensure all possible therapeutic targets are accounted for. Once established and confirmed suitable, extensive screening can rapidly provide the data required to advance antidiabetic medicinal plants to appropriate animal models and optimal experimental designs.

Aspalathus linearis (Burm.f.) R.Dahlgren (Leguminosae) is commonly referred to as rooibos and is classified as part of the Fabaceae family. It is a shrub that grows up to 2 metres in height with small, yellow flowers and needle-shaped leaves that are bright green in colour. Upon fermentation, the leaves turn reddish-brown thus giving rise to 'fermented rooibos' as opposed to the unfermented aspalathin-rich variety commonly referred to as 'green rooibos'. Throughout this study, reference to the green and fermented extracts of A. linearis thus refer to these 'green' and 'fermented' plant preparations. The main active ingredients that have been isolated from rooibos include aspalathin and nothofagin. ${ }^{6}$

Rooibos is endemic to South Africa and is commonly consumed as a health beverage in the form of an herbal tea. While rooibos has not traditionally been used to treat diabetes, a study conducted by Kamakura et al. ${ }^{7}$ reported several antidiabetic activities for green rooibos including increased glucose uptake, AMP-activated protein kinase (AMPK) phosphorylation, protein kinase B (Akt) phosphorylation and GLUT-4 translocation in L6 myotubes. Kamakura et $a l^{7}$ further demonstrated the ability of green rooibos to suppress advanced glycation end-product (AGE)-induced oxidative stress in RIN-5F pancreatic $\beta$-cells. Additionally, green rooibos has been shown to suppress postprandial hyperglycaemia in mice and inhibited the activities of the digestive enzymes $\alpha$-amylase and $\alpha$-glucosidase in an in vitro experiment. ${ }^{8}$

An aspalathin-enriched green rooibos extract and a fermented extract of $A$. linearis have both previously demonstrated blood glucose lowering effects in streptozotocin induced diabetic rats. ${ }^{9,10}$ Furthermore, several compounds found in A. linearis including aspalathin and Z-2-( $\beta$-D-glucopyranosyloxy)-3-phenylpropenoic acid (PPAG) have previously been shown to reduce blood glucose levels in T2D ob/ob mice ${ }^{11}$ and obese insulin resistant rats, ${ }^{12}$ respectively.

A. linearis and its isolated compounds have also previously demonstrated numerous anti-obesity effects. A green extract enhanced glucose metabolism and decreased lipid accumulation as well as lipolysis in C3A hepatocytes and improved insulin sensitivity in obese insulin-resistant rats through increased GLUT-2 expression as well as increased phosphoinositide 3-kinase (PI3K)/Akt, phosphorylated AMPK and insulin receptor substrate (IRS) 1 and $2 .{ }^{13}$ Furthermore, A. linearis green extract and aspalathin both ameliorated palmitateinduced insulin resistance in 3T3-L1 adipocytes by reducing nuclear factor kappa B (NF-кB), IRS1 and phosphorylated AMPK while increasing Akt phosphorylation. ${ }^{14}$ The green extract further promoted GLUT-4 expression, however, this effect was not observed with aspalathin suggesting that the crude extract might provide additional benefits as a multitarget treatment approach compared to its isolated compounds.

Several polyphenols found in A. linearis have demonstrated pancreatic lipase inhibitory effects $^{15}$ while fermented A. linearis successfully inhibited lipid accumulation and promoted basal glucose uptake in 3T3-L1 adipocytes. ${ }^{16}$ Several anti-inflammatory and immune modulatory effects thought to involve a reduction in inflammatory cytokines such as TNF- $\alpha$, cyclooxygenase-2 (COX-2), IL-6, inducible nitric oxide synthase (iNOS), nitric oxide (NO) and NF-kB have also been documented for A. linearis, ${ }^{17,18}$ aspalathin and nothofagin. ${ }^{19-21}$

It is therefore clear that in contrast to most other African medicinal plants, $A$. linearis represents a relatively well-studied example of an antidiabetic plant with an established potential to impact multiple therapeutic targets. As such, the extensive literature evidence provides a unique comparative opportunity to explore the feasibility of target directed in vitro screening, including cellomics, as a pre-clinical tool to reveal therapeutic potential in a more cost effective and practical manner. Furthermore, despite the numerous meaningful efforts to uncover the antidiabetic properties of rooibos, some therapeutic targets still remain untested.

To date no clinical trials exploring the effects of rooibos on diabetic parameters have been conducted. Attempts to integrate the existing literature for such studies is complicated due to the use of different models, experimental setups, relevance of extract concentrations tested and untested responses to certain known therapeutic targets. The current study addresses these problems by conducting an in depth in vitro characterisation of the antidiabetic effects of both green and fermented rooibos in 5 well-characterised antidiabetic targets - i.e. the intestine, liver, skeletal muscle, adipose tissue/obesity and pancreatic $\beta$-cells. The antidiabetic screening platform consisted of 20 different screening assays incorporating both target-directed screening assays and cellomics/high-content screening.

To date, the antidiabetic potential of over 185 plant species from Africa have been investigated. ${ }^{2}$ Most of the available studies, however, remain incomplete or preliminary in nature thus leaving much of their antidiabetic potential unexplored. As neither clinical trials nor in vivo models can provide a practical short term solution, in vitro screening with its high throughput capacity represents a feasible solution. The novelty and usefulness of this screening platform thus lies in identifying the antidiabetic potential of plant extracts and/or com- 
pounds - particularly when little to no information is available. Consequently, establishment of such a screening platform can be viewed as an integral component to enable natural product antidiabetic research to progress to the point where natural products can be commercialised and incorporated into meaningful healthcare programs.

While it is acknowledged that simple monolayer cell based models may not fully replicate the complex cellular interactions as they occur in vivo, a plausible solution to overcoming the limitations of in vitro studies would be to design comprehensive screening platforms, such as the one developed during the present study, which would allow in vitro assays to compliment in vivo models. Not only will this reduce the number of animal models required by eliminating much of the guess work involved in selecting appropriate models and targets for further studies, but it will also improve confidence in the research findings and enable the identification of potential signalling pathways that may be involved.

\section{Methods and materials}

\subsection{Reagents and chemicals}

Except where specified, all chemicals and reagents were purchased from Sigma-Aldrich (St Louis, MO, USA). DMEM, RPMI-1640 and FBS were acquired from HighClone Laboratories, Inc. (South Logan, Utah, USA) while penicillinstreptomycin and PBS were purchased from Lonza (BioWhittaker, Verviers, Belgium). Phospho-NF-kB p65 (Ser536)(93H1) Rabbit mAb, Cox2 (D5H5) XP Rabbit mAb (Alexa Fluor 488 Conjugate) and iNOS (D6B6S) Rabbit mAb (PE Conjugate) antibodies were purchased from Cell Signalling Technology, Inc. (Danvers, MA, USA). Horse serum and 1\% non-essential amino acids were obtained from Biowest.

\subsection{Extract preparation}

The green and fermented extracts of A. linearis were kindly donated by Profs. E. Joubert and D. de Beer from the Agricultural Research Council (Stellenbosch, South Africa). Rooibos herbal tea (green and fermented) was obtained from Rooibos Ltd (Clanwilliam, South Africa). Extraction of the plant material was carried out using hot water as described by Joubert and de Beer. ${ }^{22}$ Briefly, $1 \mathrm{~L}$ of boiling water was added to $100 \mathrm{~g}$ of the plant material and incubated in a water bath for $30 \mathrm{~min}$ at $93{ }^{\circ} \mathrm{C}$. Extracts were then filtered through Whatman $\mathrm{nr} 4$ filter paper and freeze-dried. Retention samples of the green and fermented rooibos extracts were coded ALI_L0091_1028B1_1604 and ALI_L0193_1029B1_1604, respectively. Major phenolic compounds present in each extract was quantified as described by Walters et al. ${ }^{23}$ All stocks were prepared fresh weekly in DMSO $\left(40 \mathrm{mg} \mathrm{mL}^{-1}\right)$.

\subsection{Cell culture and maintenance}

Selected cell lines were maintained in $10 \mathrm{~cm}$ treated polystyrene Petri dishes in the relevant culture medium sup- plemented with $10 \%$ FBS as well as $1 \%(\mathrm{v} / \mathrm{v})$ penicillin/streptomycin and incubated in a humidified incubator at $37{ }^{\circ} \mathrm{C}$ with $5 \% \mathrm{CO}_{2}$. Cultures were assessed daily for contamination using an Axiovert 40C inverted microscope (Carl Zeiss, Germany) and sub-cultured when they reached approximately $80 \%$ confluence. Furthermore, the culture medium was replaced every third to fourth day to stimulate and maintain optimal growth conditions.

\subsection{Cytotoxicity screening}

Cells were seeded into TPP tissue culture treated 96-well microtiter plates at the following densities: $6 \times 10^{3}$ cells per well for C3A hepatocytes (MEM with 1\% non-essential amino acids), $3 \times 10^{4}$ cells per well for RAW 264.7 macrophages (lowglucose DMEM) and $2 \times 10^{4}$ cells per well for INS-1 pancreatic $\beta$-cells (RPMI-1640). These cells were then left to attach overnight after which they were exposed to the specified treatments. L6 myoblasts (high-glucose DMEM) were seeded at a density of $3 \times 10^{3}$ cells per well, however, they were differentiated into myotubes prior to treatment with the relevant extracts. Briefly, L6 myoblasts seeded in high-glucose DMEM containing $10 \%$ FBS were grown to $90 \%$ confluence after which the medium was replaced with high-glucose DMEM containing $2 \%$ horse serum. The myotubes were cultured in horse serum for an additional 6 days, replacing the medium every 2 nd to 3 rd day and then exposed to the relevant treatments on day 7 for 24 hours.

All extracts were tested up to a maximum concentration of $200 \mu \mathrm{g} \mathrm{mL} \mathrm{m}^{-1}$ for all cell lines. Following the appropriate treatment period, the culture medium was gently aspirated and cells were incubated in $50 \mu \mathrm{L}$ of Hoechst $33342(5 \mu \mathrm{g}$ $\mathrm{mL}^{-1}$ in PBS) at room temperature for 10 minutes protected from light. Next, $50 \mu \mathrm{L}$ of PI $\left(100 \mu \mathrm{g} \mathrm{mL}^{-1}\right.$ in PBS $)$ was added directly before image acquisition. All fluorescent micrographs were captured using the DAPI and Texas Red filter sets for Hoechst 33342 and PI, respectively. Nine image sites were acquired per well using a $10 \times$ magnification and the percentage of live and dead cells were calculated. See section 2.8 for further detail on image acquisition.

\subsection{Targeting postprandial hyperglycaemia}

2.5.1 Alpha-amylase inhibition. Alpha-amylase inhibition was measured using the colorimetric assay method used to quantify starch-iodine complexes as described by Xiao et al. ${ }^{24}$ with slight modifications. Briefly, in a 96-well microtiter plate, $15 \mu \mathrm{L}$ of test sample was incubated with $5 \mu \mathrm{L}$ porcine pancreatin $\left(1 \mathrm{mg} \mathrm{mL}^{-1}\right.$ in $1 \times$ PBS buffer solution; prepared fresh and kept on ice) for 10 minutes at $37{ }^{\circ} \mathrm{C}$. The reaction was initiated by the addition of $20 \mu \mathrm{L}$ starch solution $(2 \mathrm{mg}$ $\mathrm{mL}^{-1}$ in distilled water; boiled with continuous stirring for 15 minutes until the solution turned clear; cooled to room temperature with continuous stirring and the volume of evaporated water was replaced) and allowed to proceed for 30 minutes at $37^{\circ} \mathrm{C}$. The reaction was halted by the addition of $10 \mu \mathrm{L} \mathrm{HCl} \mathrm{(1} \mathrm{M}$ in distilled water) and $75 \mu \mathrm{L}$ iodine 
reagent $(0.127 \mathrm{~g}$ iodine and $0.083 \mathrm{~g}$ potassium iodide in $100 \mathrm{~mL}$ distilled water) and the absorbance was measured at $580 \mathrm{~nm}$. Acarbose $(500 \mu \mathrm{M}$ stock solution prepared in PBS) was included as a positive control. No enzyme and no substrate controls were included for each sample to account for the absorbance of the extracts. The absorbance of the enzyme and substrate-free wells was subtracted from the absorbance readings of the wells containing enzyme and substrate and the percentage $\alpha$-amylase inhibition was calculated using the following formula:

$\% \alpha$-amylase inhibition $=$

$\underline{\text { (amylase activity of control - amylase activity of test sample) }}$ amylase activity of control

$\times 100$

where

amylase activity $=\mathrm{A} 580 \mathrm{~nm}$ without enzyme - A $580 \mathrm{~nm}$ with enzyme.

2.5.2 Alpha-glucosidase inhibition. To measure $\alpha$-glucosidase inhibition, yeast $\alpha$-glucosidase from Saccharomyces cerevisiae was utilized using the method described by Akinloye et $a .^{25}$ with slight modifications. In a 96-well plate, $5 \mu \mathrm{L}$ of sample was incubated in the presence of $20 \mu \mathrm{L}$ enzyme $(50 \mu \mathrm{g}$ $\left.\mathrm{mL}^{-1}\right)$ and $60 \mu \mathrm{L}$ reaction buffer $(67 \mathrm{mM}$ potassium phosphate, pH 6.8 to which $3 \mathrm{mM}$ reduced glutathione was added directly before use). The reaction was pre-incubated for 5 minutes at $37{ }^{\circ} \mathrm{C}$ followed by the addition of $10 \mu \mathrm{L}$ of substrate $(10 \mathrm{mM}$ $p$-nitrophenyl $\alpha$-D-glucopyranoside). The reaction was allowed to proceed for 30 minutes at $37^{\circ} \mathrm{C}$ after which it was halted by the addition of $25 \mu \mathrm{L}$ of sodium carbonate $(100 \mathrm{mM})$. Epigallocatechin gallate (ECGC) was included as a positive control for $\alpha$-glucosidase inhibition and the quantity of $p$-nitrophenol released was determined spectrophotometrically at $405 \mathrm{~nm}$. The percentage $\alpha$-glucosidase inhibition was calculated as follows:

$$
\begin{aligned}
& \% \alpha \text {-amylase inhibition }= \\
& \frac{(\mathrm{A} 405 \mathrm{~nm} \text { of control }-\mathrm{A} 405 \mathrm{~nm} \text { of test sample })}{\mathrm{A} 405 \mathrm{~nm} \text { of control }} \times 100 .
\end{aligned}
$$

No enzyme and no substrate controls were included for each sample to account for the absorbance of the extracts. The absorbance of the enzyme and substrate-free wells was subtracted from the absorbance readings of the wells containing enzyme and substrate.

2.5.3 DPP-iv inhibition. DPP-iv inhibition was measured using the chromogenic substrate Gly-Pro $p$-nitroanilide hydrochloride (Gly-Pro pNA) in combination with recombinant human DPP-iv. In a 384-well plate, $14 \mu \mathrm{L}$ test sample (prepared in $50 \mathrm{mM}$ Tris-HCl buffer, $\mathrm{pH}$ 8.0) was pre-incubated in the presence of $0.2 \mu \mathrm{L}$ enzyme (undiluted) for 5 minutes at $37{ }^{\circ} \mathrm{C}$ in a BioTek PowerWave XS spectrophotometer (Winooski, VT, USA). After the addition of $20 \mu \mathrm{L}$ substrate (20 mM Gly-Pro pNA stock solution prepared in DMSO and diluted to $0.2 \mathrm{mM}$ with Tris- $\mathrm{HCl}$ buffer, $\mathrm{pH} 8.0$ ), the absor- bance was measured at $410 \mathrm{~nm}$ every 3 minutes for 30 minutes. Diprotin A $\left(17.5 \mu \mathrm{g} \mathrm{mL}^{-1}\right)$ was included as a positive control and the absorbance was plotted against time for each sample. The linear portion of the slope was then used to calculate the percentage DPP-iv inhibition using the following formula:

$$
\begin{aligned}
& \% \text { DPP-iv inhibition }= \\
& \frac{(\text { Gradient of control }- \text { gradient of test sample })}{\text { Gradient of control }} \times 100 .
\end{aligned}
$$

2.5.4 Glycation inhibition. The glycation inhibitory potential of A. linearis was measured using BSA as described previously by Matsuura et al. ${ }^{26}$ In an Eppendorf tube, $250 \mu \mathrm{L}$ BSA $(400 \mu \mathrm{g}), 240 \mu \mathrm{L}$ glucose $(200 \mathrm{mM})$ and $10 \mu \mathrm{L}$ test sample (all prepared in $50 \mathrm{mM}$ phosphate buffer, $\mathrm{pH}$ 7.4) were combined and heated to $60{ }^{\circ} \mathrm{C}$ in a heating block for 30 hours. After removing the samples from the heating block, they were left to cool to room temperature and $100 \mu \mathrm{L}$ was transferred into a new Eppendorf tube and placed on ice. After adding $10 \mu \mathrm{L}$ of $100 \%(\mathrm{w} / \mathrm{v})$ cold tricarboxylic acid, the sample was agitated using a vortex and centrifuged at $15000 \mathrm{~g}$ for 4 minutes at $4{ }^{\circ} \mathrm{C}$. The supernatant containing glucose and interfering substances was discarded and the pellet left to dissolve in $400 \mu \mathrm{L}$ alkaline PBS (137 mM NaCl, $8.1 \mathrm{mM} \mathrm{Na} \mathrm{HPO}_{4}, 2.68 \mathrm{mM} \mathrm{KCl}$ and $1.49 \mathrm{mM} \mathrm{KH}_{2} \mathrm{PO}_{4}, \mathrm{pH} 10.0$ ) overnight. Once the pellet was completely dissolved, samples were transferred into a 96-well plate (90 $\mu \mathrm{L}$ per well) and the fluorescence measured using the AGE excitation/emission wavelengths of $370 / 440 \mathrm{~nm}$ by means of a Fluoroskan Ascent FL fluorometer (ThermoLabsystems, Finland).

\subsection{Targeting insulin resistance and inflammation}

2.6.1 Hepatocyte glucose utilisation. C3A hepatocytes were seeded into tissue culture treated 96-well plates overnight $(1 \times$ $10^{4}$ cells per well) in MEM containing 10\% FBS and 1\% nonessential amino acids (NEAA). Cells were exposed to the specified treatments for 48 hours at $37{ }^{\circ} \mathrm{C}$. The culture medium was gently aspirated and the cells were washed with PBS $(100 \mu \mathrm{L})$. The glucose uptake was then measured by adding $25 \mu \mathrm{L}$ of incubation buffer (RPMI-1640 diluted in PBS containing $0.1 \%$ BSA to achieve a final glucose concentration of $8 \mathrm{mM}$ ). The cells were incubated for a further 4 hours at $37{ }^{\circ} \mathrm{C}$ and the glucose remaining in the medium was measured using the standard glucose oxidase/peroxidase method as described by Lott and Turner ${ }^{27}$ with modifications. Briefly, $5 \mu \mathrm{L}$ of the culture medium was transferred to corresponding wells in a new 96-well plate followed by the addition of $200 \mu \mathrm{L}$ glucose oxidase reagent ( $3 \mathrm{mM}$ phenol, $0.4 \mathrm{mM}$ 4-aminoantipyrine, $0.25 \mathrm{mM}$ EDTA and $2.5 \mathrm{U} \mathrm{mL}^{-1}$ horseradish peroxidase in $0.5 \mathrm{M}$ PBS buffer, $\mathrm{pH} 7.0 ; 1 \mathrm{mU} \mathrm{mL}^{-1}$ glucose oxidase from Aspergillus niger was added directly before use). The reaction was incubated for 15 minutes at room temperature after which the absorbance was measured at $510 \mathrm{~nm}$. Cell-free wells containing incubation buffer served as an indicator of the starting glucose concentration while the blank represents cells without treatment. The glucose con- 
sumption was calculated as a percentage of the blank using the following formula:

Glucose consumption $=$

$\frac{(\text { A } 510 \mathrm{~nm} \text { of cell-free wells }- \text { A } 510 \mathrm{~nm} \text { of test sample })}{(\text { A } 510 \mathrm{~nm} \text { of cell-free wells }- \text { A } 510 \mathrm{~nm} \text { of blank })} \times 100$.

2.6.2 Inhibition of hepatocyte lipid accumulation. C3A hepatocytes were seeded into 96-well plates overnight $\left(6 \times 10^{3}\right.$ cells per well) at $37^{\circ} \mathrm{C}$. All treatments were prepared in MEM containing $2 \%$ BSA (fatty acid-free) and 1\% NEAA (sterile-filtered using a $0.1 \mu \mathrm{m}$ syringe filter). Steatosis was induced by incubating the cells with test sample as well as $1 \mathrm{mM}$ palmitic acid (stock solution prepared in absolute ethanol and diluted in culture medium; prepared freshly before use) for 24 hours at $37{ }^{\circ} \mathrm{C}$. The lipids were then stained using LipidTox Red for neutral lipids (ThermoFisher Scientific) according to the manufacturer's instructions. Briefly, the cells were fixed by adding formaldehyde to a final concentration of $4 \%$ directly to the culture medium for 15 minutes at room temperature. The medium was gently aspirated and cells were washed with PBS. Cells were then incubated in $50 \mu \mathrm{L}$ staining solution containing Hoechst $33342\left(5 \mu \mathrm{g} \mathrm{mL}^{-1}\right.$ prepared in PBS) and LipidTox Red (diluted 1:1000 to achieve a $1 \times$ solution) for 30 minutes at room temperature protected from light. Fluorescent micrographs capturing 9 image sites per well using the Texas Red filter set were acquired and the mean stain area of LipidTox Red was calculated. See section 2.8 for further detail on image acquisition.

2.6.3 Skeletal muscle glucose utilisation and inhibition of lipid accumulation. L6 skeletal myoblasts were seeded into 96-well plates and differentiated as described in section 2.4. Cells were then exposed to the specified treatments for 24 hours at $37{ }^{\circ} \mathrm{C}$. All treatments were prepared in highglucose DMEM containing $2 \%$ BSA (fatty acid-free). Insulin resistance was induced through the addition of $1 \mathrm{mM}$ palmitic acid to the culture medium (prepared as described in section 2.6.2). Glucose utilisation was measured using the same protocol described for C3A hepatocytes (section 2.6.1) except that the incubation period was reduced to 3 hours. This was followed by lipid staining using LipidTox Red as described for C3A hepatocytes (section 2.6.2).

2.6.4 Pancreatic lipase inhibition. Porcine pancreatic lipase inhibition was measured using the chromogenic substrate $p$-nitrophenyl palmitate ( $\mathrm{pNPP})$. Sample $(10 \mu \mathrm{L})$ was preincubated at $37^{\circ} \mathrm{C}$ for 15 minutes in the presence of porcine pancreatin $\left(100 \mathrm{mg} \mathrm{mL}^{-1}\right.$ prepared in $100 \mathrm{mM}$ Tris- $\mathrm{HCl}, \mathrm{pH}$ 8.0; the solution was centrifuged at $5000 \mathrm{~g}$ for 5 minutes and the supernatant used as the source of the enzyme; the solution was kept on ice until use). Substrate $(170 \mu \mathrm{L})$ was added and the reaction allowed to proceed for a further 5 minutes at $37{ }^{\circ} \mathrm{C}$ after which the absorbance was measured at $405 \mathrm{~nm}$. The substrate solution was prepared by combining solution A containing pNPP ( $1 \mathrm{mg} \mathrm{mL} \mathrm{mL}^{-1}$ dissolved in isopropanol) with solution B containing gum arabic $\left(1 \mathrm{mg} \mathrm{mL}^{-1}\right)$, sodium deoxycholate $\left(2 \mathrm{mg} \mathrm{mL}^{-1}\right)$ and Triton $\mathrm{X}-100(5 \mu \mathrm{L}$ per $\mathrm{mL})$ prepared in $100 \mathrm{mM}$ Tris-HCl ( $\mathrm{pH}$ 8.0). The percentage pancreatic lipase inhibition was calculated as follows:

$$
\begin{aligned}
& \% \text { lipase inhibition }= \\
& \frac{\mathrm{A} 405 \mathrm{~nm} \text { of blank }-\mathrm{A} 405 \mathrm{~nm} \text { of test sample }}{405 \mathrm{~nm} \text { of blank }} \times 100 .
\end{aligned}
$$

2.6.5 Inhibition of nitric oxide production. In a 96-well plate, RAW 264.7 macrophages were seeded $\left(1 \times 10^{5}\right.$ cells per well) and left to attach at $37{ }^{\circ} \mathrm{C}$ overnight after which the culture medium was gently aspirated and replaced with the specified treatments together with LPS (200 ng $\left.\mathrm{mL}^{-1}\right)$. Following a 24 hour incubation period at $37^{\circ} \mathrm{C}$, the Griess reaction was carried out as described previously. ${ }^{28}$ Briefly, $50 \mu \mathrm{L}$ of the culture medium was transferred to corresponding wells of a new 96-well microtiter plate. After adding Griess reagent for nitrite in a 1:1 ratio, the reaction was allowed to proceed for 10 minutes at room temperature. Lastly, the absorbance was measured spectrophotometrically at $540 \mathrm{~nm}$ and the results were calculated as a percentage of the LPS control. All results were normalised for cell density using a standard crystal violet staining assay. Aminoguanidine $\left(100 \mu \mathrm{g} \mathrm{mL}{ }^{-1}\right)$, a known inhibitor of NO production, was included as a positive control.

2.6.6 Nitric oxide scavenging. The NO scavenging assay was performed as described previously with modifications. ${ }^{29}$ In a 96-well plate, test sample $(50 \mu \mathrm{L})$ was incubated in the presence of $10 \mathrm{mM}$ sodium nitroprusside $(50 \mu \mathrm{L})$ at room temperature for 150 minutes under direct light. Griess reagent $(100 \mu \mathrm{L})$ was added and incubated for a further 10 minutes at room temperature after which the absorbance was measured spectrophotometrically at $540 \mathrm{~nm}$. Aminoguanidine $(200 \mu \mathrm{g}$ $\mathrm{mL}^{-1}$ ) was included as a positive control and the percentage of NO scavenged was calculated as follows:

$$
\begin{aligned}
& \% \text { NO scavenging }= \\
& \frac{\text { A } 540 \mathrm{~nm} \text { of control }- \text { A } 540 \mathrm{~nm} \text { of test sample }}{\text { A } 540 \mathrm{~nm} \text { of control }} \times 100 .
\end{aligned}
$$

2.6.7 Immunofluorescent detection of iNOS, COX-2 and NF-кB. COX-2, iNOS and phosphorylated NF-кB levels were measured in LPS-activated RAW 264.7 macrophages using fluorescent antibodies. Cells were seeded into sterile 96-well plates $\left(3 \times 10^{4}\right.$ cells per well $)$ and left to attach at $37{ }^{\circ} \mathrm{C}$ overnight. Cells were then incubated for a further 24 hours in the presence of A. linearis as well as LPS (200 $\mathrm{ng} \mathrm{mL}{ }^{-1}$ ) for the COX-2 and iNOS assays. For NF-кB nuclear translocation, cells were incubated in the presence of $A$. linearis extracts for 24 hours with LPS only being added during the final 60 minutes of incubation. For COX-2 and NF- $\mathrm{kB}$, cells were fixed in a fume hood with formaldehyde ( $4 \%$ final concentration added directly to the culture medium) for 15 minutes at room temperature. After gently aspirating the fixative and washing twice with PBS $(100 \mu \mathrm{L})$, the cells were permeabilised in ice-cold methanol $(100 \mu \mathrm{L})$ for 10 minutes at $-20^{\circ} \mathrm{C}$. After aspirating the methanol, cells were incubated in PBS for 5 minutes at room temperature. For iNOS, cells were fixed and permeabilised using the 
IntraPrep permeabilisation reagent kit (Beckman Coulter) according to the manufacturer's instructions.

Following fixation and permeabilisation, all cells were washed twice with a $1 \%$ solution of BSA prepared freshly in PBS and incubated in blocking solution (3\% BSA solution containing $0.2 \%$ Triton-X 100 prepared fresh in PBS) for 45 minutes at room temperature. The blocking solution was gently aspirated and the cells were incubated in $50 \mu \mathrm{L}$ of the relevant antibody for 1 hour at $37^{\circ} \mathrm{C}$. Phospho-NF-кB p65 (Ser536)(93H1) Rabbit mAb, Cox2 (D5H5) XP Rabbit mAb (Alexa Fluor 488 Conjugate) and iNOS (D6B6S) Rabbit mAb (PE Conjugate) antibodies were prepared in 1\% BSA/PBS using $1: 800$ dilutions. Care was taken to keep the cells out of direct light and plates were wrapped in tinfoil to prevent quenching of the antibodies.

For NF- $\kappa \mathrm{B}$, the primary antibody was gently aspirated and cells were washed twice with a $1 \%$ BSA/PBS solution $(100 \mu \mathrm{L})$. Cells were then incubated in $50 \mu \mathrm{L}$ of Anti-Mouse IgG $(\mathrm{H}+\mathrm{L}) \mathrm{F}\left(\mathrm{ab}^{\prime}\right) 2$ Fragment (Alexa Fluor 488 Conjugate) using a 1:1000 dilution for 60 minutes at $37^{\circ} \mathrm{C}$ protected from light. This step was skipped for COX-2 and iNOS staining as the primary antibodies were already conjugated to fluorescent dyes. All cells were then washed twice with PBS and the nuclei were stained for 10 minutes using Hoechst $33342\left(5 \mu \mathrm{g} \mathrm{mL}{ }^{-1}\right.$ in PBS) at room temperature. Fluorescent micrographs were captured using a $40 \times$ objective for NF- $\mathrm{BB}$ and a $20 \times$ objective for iNOS and COX-2 with nine image sites acquired per well. NF- $\kappa \mathrm{B}$ and COX-2 were acquired using the FITC filter set while iNOS was acquired using the TRITC filter set. See section 2.8 for further detail on image acquisition.

\subsection{Targeting pancreatic beta-cell function}

2.7.1 Calcium dependent insulin secretion. INS-1 pancreatic $\beta$-cells were seeded into 96-well microtiter plates $\left(1 \times 10^{4}\right.$ cells per well) in RPMI-1640 medium with 10\% FBS and incubated at $37^{\circ} \mathrm{C}$ for 48 hours. After the incubation period, the medium was gently aspirated and cells were loaded with dye by incubating them in $50 \mu \mathrm{L}$ of staining solution containing $2 \mu \mathrm{M}$ Fluo-4 AM (ThermoFisher Scientific) and Hoechst $33342\left(5 \mu \mathrm{g} \mathrm{mL}{ }^{-1}\right)$ prepared in PBS $\left(+\mathrm{Ca}^{2+} / \mathrm{Mg}^{2+}\right)$ for 45 minutes at $37{ }^{\circ} \mathrm{C}$ protected from light. The staining solution was then gently aspirated and the cells were incubated in PBS $(50 \mu \mathrm{L})$ for a further 30 minutes at $37{ }^{\circ} \mathrm{C}$. Finally, cells were incubated in the presence of the specified treatments prepared in PBS $\left(+\mathrm{Ca}^{2+} / \mathrm{Mg}^{2+}\right)$ for 10 minutes at $37{ }^{\circ} \mathrm{C}$ after which fluorescent micrographs were captured. Nine image sites were acquired per well using the DAPI and FITC filter sets. See section 2.8 for further detail on image acquisition.

2.7.2 Ferric reducing antioxidant power (FRAP) assay. The FRAP assay was conducted as previously described by Boukes and van de Venter. $^{30}$ Into a 96-well plate, FRAP reagent $(200 \mu \mathrm{L})$ was added to $50 \mu \mathrm{L}$ of sample. The tested sample concentrations ranged from 0 to $200 \mu \mathrm{g} \mathrm{mL}{ }^{-1}$. The FRAP reagent was prepared by combining $20 \mathrm{~mL}$ sodium acetate buffer
(300 mM) with $2 \mathrm{~mL}$ TPTZ $(10 \mathrm{mM}), 2 \mathrm{~mL}$ ferric chloride (20 $\mathrm{mM}$ in distilled water) and $2.4 \mathrm{~mL}$ distilled water and was prepared fresh on the day of use. After a 30 minutes incubation period at $37{ }^{\circ} \mathrm{C}$, the absorbance was measured at $593 \mathrm{~nm}$. Absorbance values were plotted against the concentration of each extract to obtain the gradient of the slope. The results were then expressed as Trolox equivalents (TE) using the following equation:

$$
\begin{aligned}
\text { Trolox equivalents }(\mathrm{g} / \mathrm{g})= & \text { Gradient of trolox } \\
& - \text { gradient of sample. }
\end{aligned}
$$

2.7.3 DPPH free radical scavenging assay. To measure the $\mathrm{DPPH}$ radical scavenging ability of $A$. linearis, sample $(5 \mu \mathrm{L})$ was incubated in the presence of $120 \mu \mathrm{L}$ Tris-HCl buffer (50 mM; pH 7.4) as well as $120 \mu \mathrm{L}$ of DPPH (0.1 mM prepared in absolute ethanol) in a 96-well microtiter plate for 20 minutes at room temperature. The reaction was protected from light and the absorbance was subsequently measured at $513 \mathrm{~nm}$. The percentage radical scavenging activity was calculated using the following formula:

$$
\begin{aligned}
& \% \mathrm{DPPH} \text { scavenging }= \\
& \frac{\mathrm{A} 513 \mathrm{~nm} \text { of control }- \text { A } 513 \mathrm{~nm} \text { of test sample }}{\text { A } 513 \mathrm{~nm} \text { of control }} \times 100 .
\end{aligned}
$$

2.7.4 CellROX Orange. The ability of $A$. linearis to protect INS-1 cells against tert-Butyl hydroperoxide (TBHP)-induced oxidative stress was measured using the CellROX Orange reagent (ThermoFisher Scientific). INS-1 cells were seeded into 96-well plates $\left(2 \times 10^{4}\right.$ cells per well $)$ overnight at $37{ }^{\circ} \mathrm{C}$ and then pre-treated with the specified extracts for 24 hours at $37^{\circ} \mathrm{C}$. Oxidative stress was then induced by adding TBHP $(30 \mu \mathrm{M})$ directly to the culture medium without removing the extract containing spent medium. Following a 2 hour incubation period at $37^{\circ} \mathrm{C}$, the medium was gently aspirated. The quantity of ROS was measured by staining the cells with the CellROX Orange reagent $(5 \mu \mathrm{M})$ for 30 minutes at $37{ }^{\circ} \mathrm{C}$. Hoechst $33342\left(5 \mu \mathrm{g} \mathrm{mL}^{-1}\right)$ was included in the staining solution to enable the identification of individual cells. The reaction was protected from light and fluorescent micrographs were captured, acquiring nine image sights per well using a $10 \times$ objective with the DAPI and Texas Red filter sets. Antioxidant activity was determined using the mean stain area for CellROX Orange. This activity reflects a combination of both the direct ROS scavenging effect (intracellular and extracellular) as well as any potential changes in the inherent capacity of the cell to resist oxidative stress. See section 2.8 for further detail on image acquisition.

2.7.5 Beta cell proliferation and promotion of cell survival. To measure $\beta$-cell proliferation, INS-1 cells were seeded into 96-well plates $\left(2 \times 10^{4}\right.$ cells per well $)$ in RPMI-1640 medium with $10 \%$ FBS and incubated overnight at $37{ }^{\circ} \mathrm{C}$. Cells were then exposed to the specified treatment conditions over 24 hours after which the total cell numbers were calculated from fluorescent micrographs using Hoechst $33342\left(5 \mu \mathrm{g} \mathrm{mL} \mathrm{mL}^{-1}\right)$ staining as described previously. The same protocol was used 
to measure promotion of cell survival in INS-1 cells with the addition of $3.5 \mu \mathrm{M}$ TBHP in the culture medium to promote oxidative stress-induced cell death. See section 2.8 for further detail on image acquisition.

\subsection{Imaging, data- and statistical analysis}

All fluorescent micrographs were captured using Molecular Devices ImageXpress Micro XLS Widefield Microscope for high content analysis and were analysed by means of MetaXpress 6.1 High Content Image Acquisition and Analysis Software using the Multi-Wavelength Cell Scoring application module. For the purpose of statistical analysis all experiments were conducted three times, each in triplicate. The standard deviation is expressed through the use of error bars and was calculated from the mean of three independent experiments. Using the ANOVA and two-tailed Student's $t$-test functions from Microsoft Excel's data analysis package, the means of the data sets were compared. The data was only considered significant in cases where $p<0.05 .^{31}$

\section{Results and discussion}

\subsection{Basal cytotoxicity screening}

As the toxicity of $A$. linearis has previously been explored in both in vitro and in vivo settings, the risk for severe toxicity appears low. In order to select suitable experimental concentrations which eliminate the confounding problems associated with cell death and that could be considered biologically relevant, the cytotoxicity of the green and fermented extracts of A. linearis were tested on four different cell lines using Hoechst 33342 (Fig. 1) and propidium iodide (PI) dual-staining. Results from PI staining were not shown in Fig. 1 due to the low number of cells that stained positive with significant increases reported in the text only. In the present study, responses were considered (i) non-toxic in cases where no significant decreases in total cell number or increases in PI staining were recorded, (ii) cytostatic if a significant decrease in total cell number was not accompanied by a significant increase in PI staining and (iii) cytotoxic in cases where a significant decrease in total cell number was accompanied by a significant increase in PI staining.

To date, no reports of toxicity for A. linearis at concentrations normally consumed in its tea form have been recorded and it is thus generally considered safe for consumption. ${ }^{32}$ The green and fermented extracts of A. linearis were, however, found to promote moderate to mild cytostatic responses in C3A hepatocytes from $150 \mu \mathrm{g} \mathrm{mL}^{-1}$ (Fig. 1A). Additionally, the green extract induced a moderate cytostatic response in activated RAW 264.7 macrophage-like cells from $100 \mu \mathrm{g} \mathrm{mL}^{-1}$ while the fermented extract induced a seemingly cytostatic response from 50 to $150 \mu \mathrm{g} \mathrm{mL} \mathrm{m}^{-1}$ (Fig. 1C) as a statistically significant $(p>0.05)$ increase in PI staining was only observed at $200 \mu \mathrm{g} \mathrm{mL} \mathrm{m}^{-1}$. No cytotoxic or cytostatic responses were recorded for differentiated L6 cells (Fig. 1B) or INS-1 pancreatic $\beta$-cells (Fig. 1D). Several publications have confirmed the noncytotoxic nature of $A$. linearis. ${ }^{33,34}$ and others

\subsection{Targeting postprandial hyperglycaemia}

Postprandial hyperglycaemia is present in both T1D and T2D and presents an attractive antidiabetic target as treatment thereof has been found to reduce oxidative stress, inflammation, NF- $\mathrm{kB}$ activation, myocardial blood flow as well as endothelial dysfunction. ${ }^{35}$ Carbohydrates account for approximately 40 to 45 percent of the daily caloric intake by humans and are thus important contributors to postprandial hyperglycaemia. $^{36}$

While digestive enzymes do not directly regulate blood glucose levels, the pharmacological inhibition of these enzymes, particularly those responsible for breaking down carbohydrates into simple sugars, can counterbalance the inadequate glucose disposal observed in diabetes and thereby reduce the occurrence of postprandial hyperglycaemia. Furthermore, these enzymes occur at the top of the starch digestion cascade and their inhibition will consequently also limit the availability of substrates for other digestion enzymes which are ultimately responsible for liberating glucose. ${ }^{37}$

To this end, the $\alpha$-amylase (Fig. 2A) and $\alpha$-glucosidase (Fig. 2B) inhibitory potentials of the green and fermented extracts of $A$. linearis were assessed. A. linearis green extract significantly inhibited the activity of $\alpha$-amylase in a dose-dependent manner, however, these responses were considered weak as they did not exceed $15 \%$ inhibition (Fig. 2A). A previous report on the effects of $A$. linearis green extract on postprandial hyperglycaemia in a non-diabetic mouse model revealed that it significantly suppressed postprandial blood glucose elevations in response to oral glucose administration as well as other carbohydrates such as maltose and starch. This was suggested to be due to reduced glucose absorption in the gut as well as the action of natural $\alpha$-amylase and $\alpha$-glucosidase inhibitors. ${ }^{8}$

The results from the current study confirm these findings as the green extract of $A$. linearis promoted a robust increase in $\alpha$-glucosidase inhibition of 63 to $86 \%$ at extract concentrations ranging from 100 to $500 \mu \mathrm{g} \mathrm{mL} \mathrm{mL}^{-1}$ (Fig. 2B). Rather weak $\alpha$-amylase inhibition was documented during the present study $\left(13 \%\right.$ at $\left.500 \mu \mathrm{g} \mathrm{mL}^{-1}\right)$; however, the study conducted by Mikami et $a l .{ }^{8}$ tested excessive extract concentrations between 2.5 and $40 \mathrm{mg} \mathrm{mL}^{-1}$ compared to the maximum concentration of $500 \mu \mathrm{g} \mathrm{mL}^{-1}$ tested during the current study. The fermented extract demonstrated marginally superior $\alpha$-glucosidase inhibitory effects of 85 to $95 \%$ at the tested concentrations (Fig. 2B).

Great research efforts are currently being focused on identifying new DPP-iv inhibitors as a treatment strategy for T2D. This is because DPP-iv inhibitors successfully inhibit the action of the principle enzyme which prevents the degradation of endogenous incretins such as GLP-1 and GIP. Consequently, active incretin concentrations rise and a significant lowering of both fasting and postprandial glucose levels due to improved $\beta$-cell responsiveness as well as the suppression of glucagon secretion is observed. ${ }^{38}$ Because GLP-1 activity is glucose-dependent, the risk of hypoglycaemia is greatly 
A

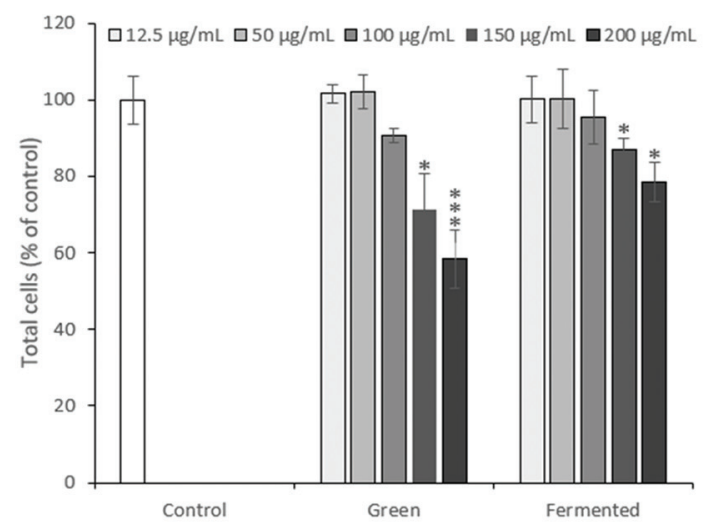

C

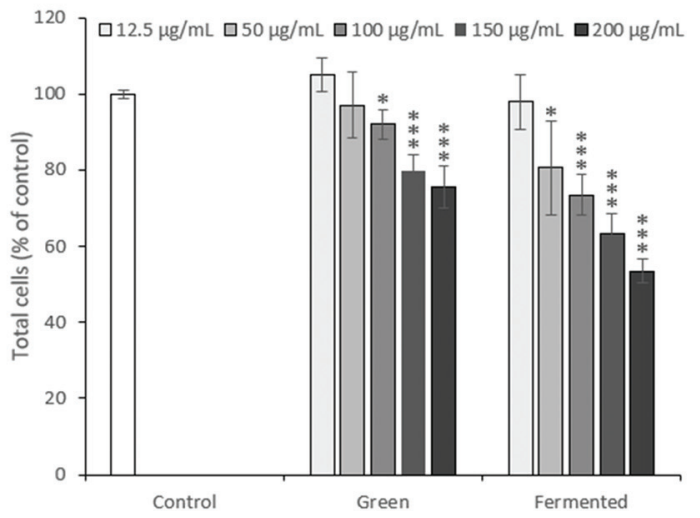

B

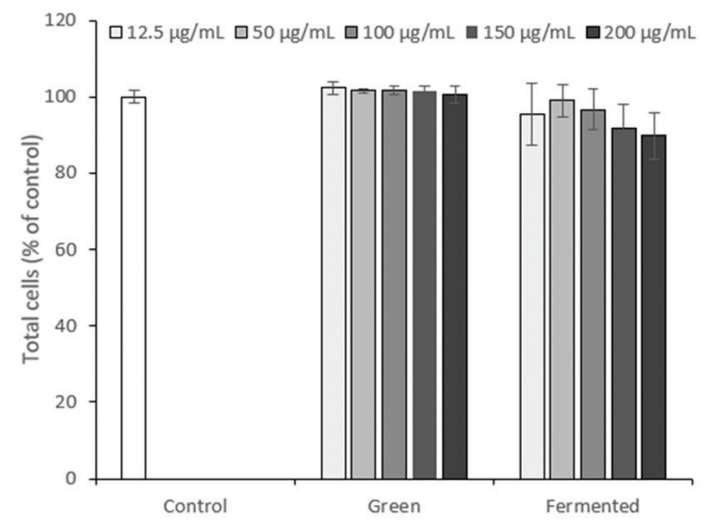

D

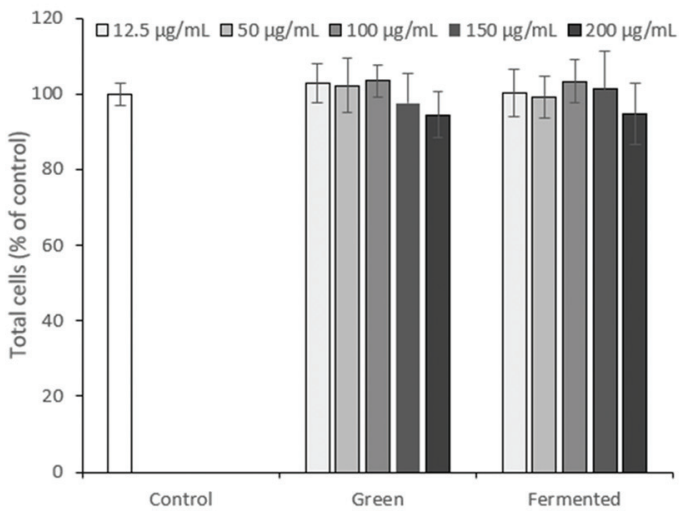

Fig. 1 Cytotoxicity screening of $A$. linearis green and fermented extracts comparing results obtained for (A) C3A hepatocytes after 48 hours, (B) differentiated L6 myotubes after 24 hours, (C) RAW 264.7 macrophages in the presence of LPS after 48 hours and (D) INS-1 pancreatic $\beta$-cells after 24 hours. Cytotoxicity was measured using Hoechst 33342 and propidium iodide (PI) staining. Results are reported as the mean \pm standard deviation (error bars shown in black) with each experiment performed three times, each in triplicate ( $T$-test: ${ }^{*} p>0.05,{ }^{* *} p<0.01,{ }^{* * *} p<0.005$ compared to control).

reduced. Furthermore, GLP-1 has been shown to stimulate $\beta$-cell proliferation in the pancreas. ${ }^{39}$

While the green and fermented extracts of A. linearis demonstrated significant DPP-iv inhibitory activities (Fig. 3A), neither of these values exceeded $30 \%$ when tested at a concentration of $100 \mu \mathrm{g} \mathrm{mL}^{-1}$. It is tempting to say that these are promising results; however, the reality is that the concentrations of extract that will be required to achieve $50 \%$ inhibition of DPP-iv activity will most likely exceed $200 \mu \mathrm{g} \mathrm{mL} \mathrm{m}^{-1}$. Unlike the inhibitors of carbohydrate digesting enzymes which exert their effects directly in the gastrointestinal tract, DPP-iv inhibitors are required to cross the intestinal brush border and be absorbed into the blood stream to exert their effects. While the concentrations used for intestinal enzyme inhibition were substantially higher than $200 \mu \mathrm{g} \mathrm{mL}^{-1}$, absorption/bioavailability requirements of DPP-iv inhibitors places into question the physiological relevance of such activity. This is confirmed by the lack of published data and in vivo studies regarding the DPP-iv inhibitory potential of A. linearis.

It is well accepted that AGEs not only contribute substantially to oxidative stress and inflammation in diabetes, but also play a large role in the development of long-term diabetic complications. While little is known regarding the role of AGEs in glucose homeostasis, it has previously been postulated that AGEs could promote glycaemic impairment through the activation of oxidative, ER and inflammatory stress in insulin-sensitive tissues. ${ }^{40}$ To this end, AGEs have been shown to impair in vitro glucose disposal in 3T3-L1 adipocytes. ${ }^{41,42}$ More recently, chronically administered AGE-albumin was shown to impair glycaemic homeostasis regardless of whether hyperglycaemia was present in rat skeletal muscle cells. This was shown to be due to the activation of inflammatory and ER stress which ultimately repressed GLUT- 4 expression. ${ }^{40}$

There is thus a real possibility that AGEs could worsen glycaemic control in diabetic individuals through the impairment of postprandial glucose disposal. Consequently, pharmacologic anti-AGE therapies are under current investigation. While their efficacy remains to be proven, reducing endogenous levels of hyperglycaemia-induced AGE formation is sure to provide lasting benefits against both diabetes and its complications. ${ }^{43}$ Consequently, the glycation inhibitory potential of A. linearis was also explored (Fig. 3B). 
A

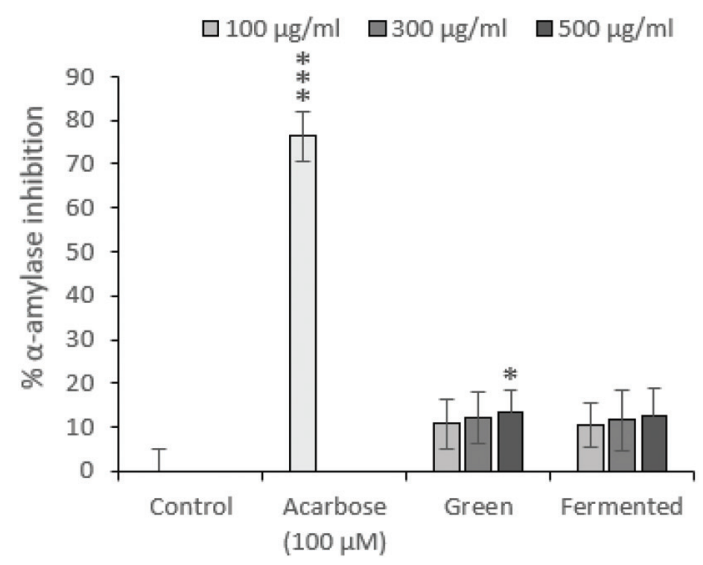

B

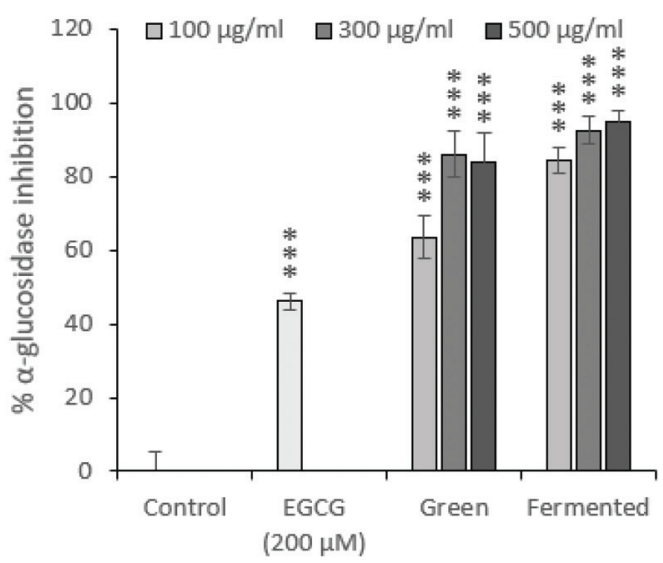

Fig. 2 Comparison of (A) the $\alpha$-amylase inhibitory potential of $A$. linearis using a colorimetric assay to quantify starch-iodine complexes with (B) $\alpha$-glucosidase inhibitory activities. Acarbose and epigallocatechin gallate (EGCG) were included as positive controls for the inhibition of $\alpha$-amylase and $\alpha$-glucosidase activities, respectively. Results are reported as the mean \pm standard deviation (error bars shown in black) with each experiment performed three times, each in triplicate $\left(T\right.$-test: ${ }^{*} p<0.05 ;{ }^{* *} p<0.01 ;{ }^{* *} p<0.005$ compared to control).

A

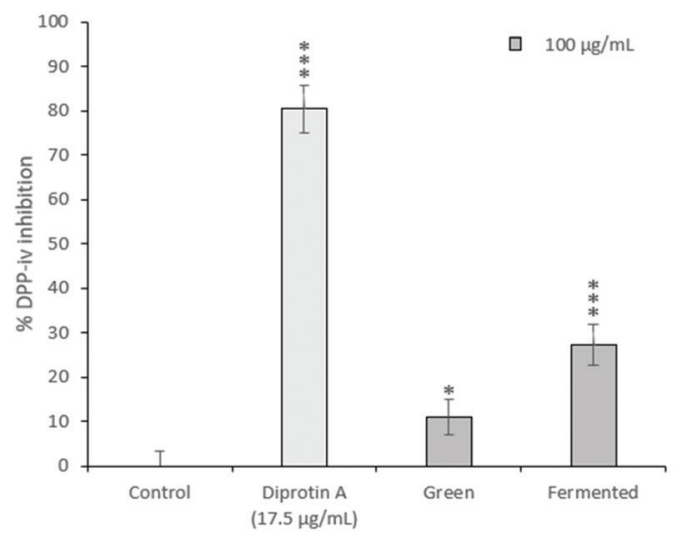

B

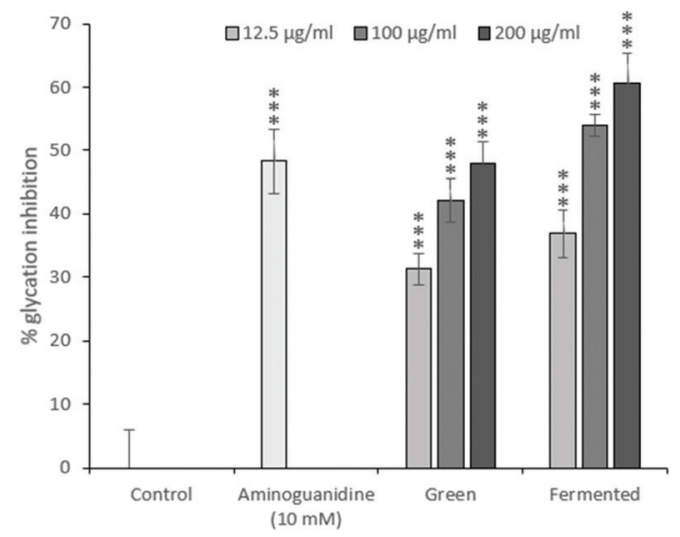

Fig. 3 The in vitro (A) DPP-iv inhibitory effects of $A$. linearis using human recombinant DPP-iv and (B) glycation inhibitory effects using glycated BSA. Diprotin A $\left(17.5 \mu \mathrm{g} \mathrm{mL}^{-1}\right)$ and aminoguanidine $(10 \mathrm{mM})$ were included as positive controls for DPP-iv inhibition and glycation inhibition, respectively. Results are reported as the mean \pm standard deviation (error bars shown in black) with the DPP-iv experiment performed once in triplicate and the glycation inhibition experiment performed three times, each in triplicate ( $T$-test: ${ }^{*} p<0.05 ; * \star p<0.01 ;{ }^{* * *} p<0.005$ compared to control).

At $200 \mu \mathrm{g} \mathrm{mL}^{-1}$, A. linearis green extract demonstrated the same glycation inhibitory potential of $48 \%$ as the positive control, aminoguanidine $(10 \mathrm{mM})$, whereas the glycation inhibitory potential of the fermented extract exceeded that of aminoguanidine at concentrations as low as $100 \mu \mathrm{g} \mathrm{mL}^{-1}$ (54\%). The glycation inhibitory potential of A. linearis has previously been demonstrated both in vitro and in vivo. Kamakura et al. previously showed that a green rooibos extract successfully reduced ROS levels induced by AGEs in RIN-5F pancreatic $\beta$-cells. ${ }^{7}$ During a study conducted by Kinae et al. ${ }^{44}$ a fermented extract of $A$. linearis successfully suppressed the formation of glycated albumin by almost $30 \%$ at a concentration of $200 \mu \mathrm{g} \mathrm{mL} \mathrm{m}^{-1}$ while a study investigating the antidiabetic potential of fermented $A$. linearis demonstrated a marked reduction of AGEs in the plasma of streptozotocin-induced diabetic rats in response to both alkaline and aqueous extracts. ${ }^{45}$

\subsection{Targeting insulin resistance and inflammation}

Insulin resistance is a key antidiabetic target, however, very few animal models display both hyperglycaemia and insulin resistance simultaneously. Furthermore, animal models of insulin resistance are frequently accompanied by several disadvantages and frequently display limited translational value. ${ }^{46}$ In vitro studies thus remain crucial in identifying natural products with this mode of action. To this end, both hepatic and skeletal muscle glucose utilisation and inhibition of lipid accumulation were explored using palmitic acid to model free fatty acid (FFA)-induced insulin resistance and lipid accumulation.

Upon examination of the potential of A. linearis to promote normal hepatic function, the green extract marginally stimulated hepatic glucose utilisation $(12.7 \%)$ at higher concen- 
A

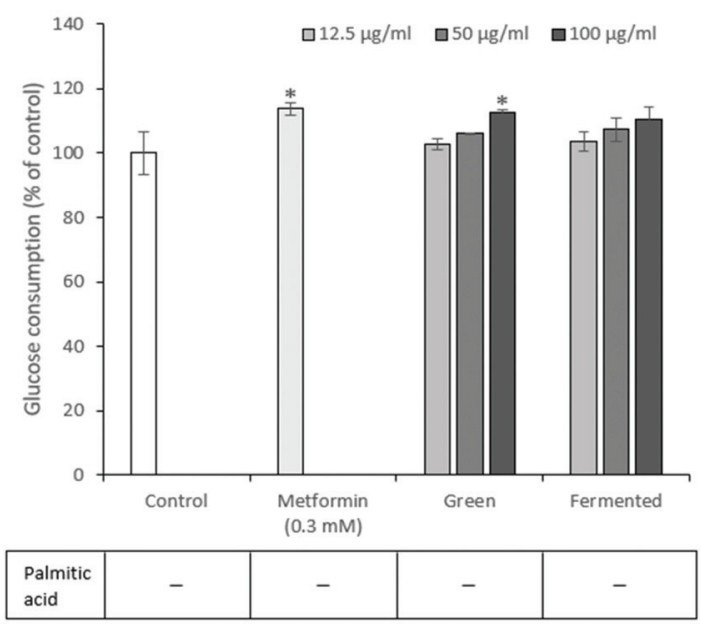

C

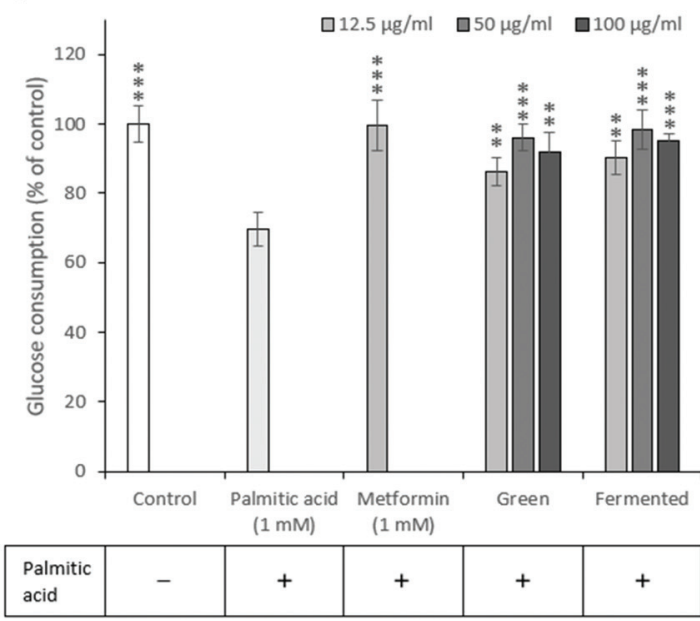

B

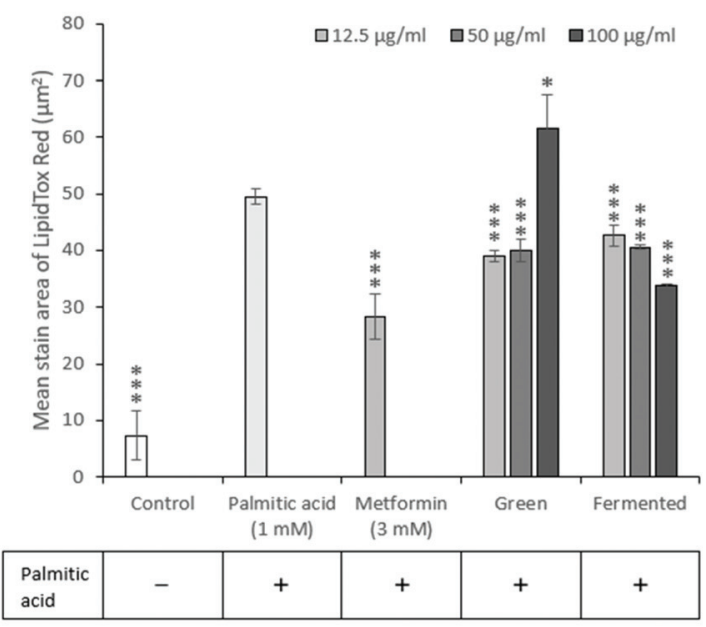

D

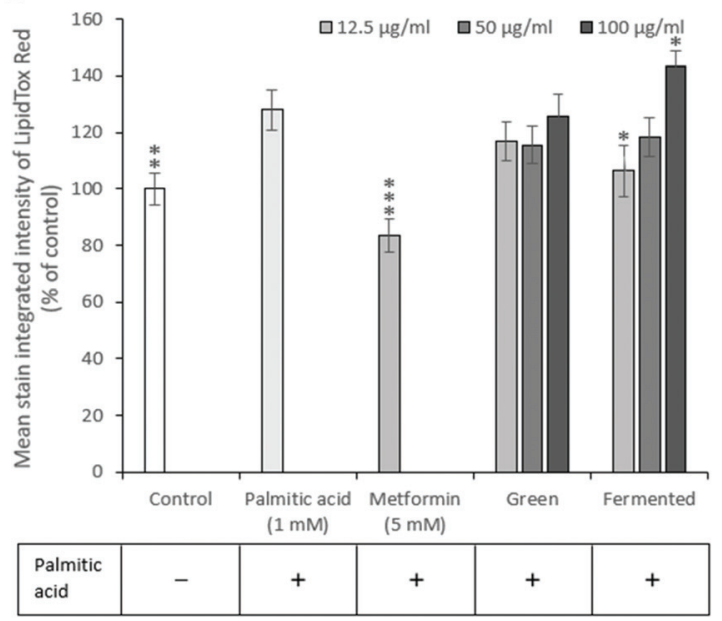

Fig. 4 A comparison of glucose consumption and the inhibition of lipid accumulation in C3A hepatocytes and differentiated L6 skeletal myotubes in the presence of $A$. linearis demonstrating (A) glucose consumption in C3A hepatocytes after 4 hours following a 48 hour treatment period. All values were normalised for cell density using the crystal violet assay ( $T$-test: ${ }^{*} p>0.05,{ }^{* *} p<0.01,{ }^{* \star} p<0.005$ compared to control); (B) lipid staining in C3A hepatocytes after a 24 hour treatment period with palmitic acid in the presence of $A$. linearis; (C) glucose consumption in differentiated L6 skeletal myotubes after 3 hours following a 24 hour treatment period. Palmitic acid was used to induce an insulin resistant state while metformin was included as a positive control for increased skeletal muscle glucose uptake; and (D) lipid accumulation in differentiated L6 skeletal muscle cells in the presence of palmitic acid after 24 hours. Metformin was included as a positive control to prevent the palmitic acid-induced accumulation of lipids. All results are reported as the mean \pm standard deviation (error bars shown in black) with all experiments performed three times, each in triplicate ( $T$-test: ${ }^{*} p<0.05 ;{ }^{* *} p<0.01 ;{ }^{* * *} p<0.005$ compared to palmitic acid control).

trations $\left(100 \mu \mathrm{g} \mathrm{mL} \mathrm{m}^{-1}\right)$ (Fig. $\left.4 \mathrm{~A}\right)$. While A. linearis green extract significantly reduced FFA-induced lipid accumulation $(p<$ $0.005)$ in hepatocytes at concentrations lower than $100 \mu \mathrm{g}$ $\mathrm{mL}^{-1}$, a dramatic increase in lipid accumulation was observed at the highest tested concentration (Fig. 4B). The increase in the mean stain area of the lipids at $100 \mu \mathrm{g} \mathrm{mL} \mathrm{m}^{-1}$ for A. linearis green extract was not accompanied by a reduction in total cell numbers (results not shown) compared to the palmitic acid control. A recent study conducted by Mazibuko-Mbeje et al. ${ }^{13}$ demonstrated that a green extract of A. linearis significantly improved hepatic energy metabolism by promoting hepatic glucose and lipid uptake in palmitic acid-induced insulin resistant C3A hepatocytes at a concentration of $10 \mu \mathrm{g} \mathrm{mL} L^{-1}$.
This was shown to be due to the enhanced phosphorylation of AKT and AMPK as well as a reduction in gluconeogenesis due to increased FoxO1 expression.

The increase in lipid accumulation observed for A. linearis green extract at $100 \mu \mathrm{g} \mathrm{mL} \mathrm{m}^{-1}$ (Fig. 4B) could thus either be due to an increase in lipid synthesis as a result of enhanced Akt phosphorylation or due to the increased uptake of lipids. An earlier study reported similar hepatoprotective and hypolipidemic effects of an aqueous rooibos extract in mice fed a high fat diet. ${ }^{47}$ During this study, a decrease in serum triglycerides was accompanied by a decrease in hepatic steatosis due to enhanced AMPK activation in the liver. Consequently, hepatocytes were converted from an ATP-consuming to an 
ATP-producing state thus promoting fatty acid and glucose oxidation.

It is thus more likely that the increase in lipid accumulation observed at higher concentrations for A. linearis green extract during the present study was due to enhanced fatty acid uptake that perhaps exceeded the rate of fatty acid oxidation in C3A hepatocytes. Regardless of the cause of increased lipid droplet size at higher concentrations, A. linearis green extract was not found to promote palmitic acid-induced lipotoxicity. Conversely, A. linearis fermented extract was shown to effectively reduce palmitic acid-induced lipid accumulation in a dose-dependent manner at concentrations ranging from 12.5 to $100 \mu \mathrm{g} \mathrm{mL} \mathrm{m}^{-1}$ with no accompanying increase in lipid accumulation at higher concentrations (Fig. 4B).

In the presence of palmitic acid, skeletal muscle glucose uptake in insulin resistant L6 myotubes was greatly enhanced in the presence of A. linearis (Fig. 4C) with the strongest response of $27 \%(p<0.005)$ and $29 \%(p<0.005)$ recorded for the green and fermented extracts, respectively, at $50 \mu \mathrm{g} \mathrm{mL}{ }^{-1}$. Green and fermented extracts of $A$. linearis thus exerted almost identical effects with regards to skeletal muscle glucose utilisation. These effects have been confirmed for the green extract with a previous study showing that cultured L6 myotubes demonstrated a significant dose-dependent increase in glucose utilisation for extract concentrations ranging from 400 to $800 \mu \mathrm{g} \mathrm{mL}{ }^{-1}$ in the absence of insulin. ${ }^{7}$ This was shown to be due to the dual activation of both Akt and AMPK. Compared to aspalathin alone, the green rooibos extract exerted a more dominant effect and the overall glucose stimulating effect of $A$. linearis green extract was thus concluded to be due to the combined synergistic activity of several compounds including aspalathin and various other polyphenols.

An earlier study conducted by Mazibuko et $a{ }^{48}$ also reported enhanced glucose utilisation in palmitic acidinduced insulin resistant $\mathrm{C} 2 \mathrm{C} 12$ muscle cells with the green extract demonstrating a stronger effect than the fermented extract at $10 \mu \mathrm{g} \mathrm{mL} \mathrm{m}^{-1}$. In addition to upregulating the protein levels of GLUT-4, possible mechanistic pathways that were explored include the down-regulation of PKC $\theta$ activation as well as the increased activation of Akt and AMPK which are key regulatory signalling molecules involved in insulin-dependent and insulin-independent signalling pathways in skeletal muscle cells.

In addition to promoting glucose uptake, the fermented extract of $A$. linearis also significantly reduced FFA-induced lipid accumulation in L6 myotubes (Fig. 4D) by $22 \%(p<0.05)$ at $12.5 \mu \mathrm{g} \mathrm{mL}{ }^{-1}$. Higher concentrations were found to have the opposite effect with increasing extract concentrations promoting FFA-induced lipid accumulation such that the lipid levels exceeded those induced by palmitic acid alone by $15 \%$ at $100 \mu \mathrm{g} \mathrm{mL}^{-1}(p<0.05)$. This was accompanied by a significant increase in total cell number $(p<0.05)$ back to levels observed for the palmitic-acid free control (results not shown) and the fermented extract of $A$. linearis was thus more than likely exerting a protective effect rather than promoting the palmitic acidinduced lipotoxicity.
Due to the success of pancreatic lipase inhibitors in treating obesity and lipid dysregulation associated with insulin resistance and T2D, the presence of natural pancreatic lipase inhibitors in A. linearis green and fermented extracts was assessed using porcine pancreatic lipase in combination with the synthetic substrate $p$-nitrophenyl palmitate. Neither the green nor the fermented extract of $A$. linearis demonstrated any significant pancreatic lipase inhibitory effects up to a concentration of $500 \mu \mathrm{g} \mathrm{mL}^{-1}$ (results not shown).

Revealing the close link between chronic low-grade inflammation and metabolic diseases such as obesity, insulin resistance and T2D has generated a novel research avenue through which these diseases can be targeted. ${ }^{49}$ Due to the numerous pathway intermediates involved in inflammation, combatting chronic inflammation could provide astronomical benefits during the treatment of insulin resistance and T2D. To date, several nonsteroidal anti-inflammatory drugs have demonstrated promising antidiabetic effects in various preclinical and clinical models. Two such drugs include salsalate which was shown to improve glycaemic control in patients with T2D and naproxen which inhibited glycogen synthase kinase during in vitro enzyme inhibition assays and in vivo studies. ${ }^{50,51} A$. linearis was thus screened for potential antiinflammatory activity using activated RAW 264.7 macrophages (Fig. 5).

While the exact role of NO in the development of insulin resistance is still under investigation, previous studies have shown that iNOS promotes the proteasomal degradation of IRS-1. Furthermore, ablation of the iNOS gene in mice fed on a high-fat diet improved glucose tolerance, promoted insulin sensitivity and prevented impairments in the PI3K/Akt signalling pathway. ${ }^{52}$ NO has thus emerged as a key mediator of both energy metabolism as well as body composition that exerts its effects primarily through regulating insulin sensitivity and oxidative capacity in adipose tissue. ${ }^{53}$ Subsequently, the ability of $A$. linearis to inhibit NO production was assessed using LPS-activated RAW 264.7 macrophages to recreate the pro-inflammatory phenotype of macrophages typically present in adipose tissue during insulin resistance and obesity.

The green extract of $A$. linearis demonstrated great potential as an anti-inflammatory therapy due to its ability to effectively reduce NO by $21.5 \%$ (Fig. 5A), iNOS by $20 \%$ (Fig. 5C) and COX-2 levels by $18 \%$ (Fig. 5D) in LPS-activated macrophages. This was shown to be at least partly due to the NO scavenging ability of this extract (Fig. 5B) as well as its capacity to reduce NF-кB nuclear translocation by almost 18\% (Fig. 5E). A slightly more complex scenario was documented for the fermented extract as it moderately reduced NO levels by $24 \%$ (Fig. 5A) yet had no effect on iNOS (Fig. 5C). This reduction in NO levels thus appears to be solely due to the strong NO scavenging ability of this extract (Fig. 5B). Furthermore, A. linearis fermented extract stimulated LPS-induced COX-2 to levels almost double that of the LPS treatment alone at the highest tested concentration (Fig. 5D) yet significantly reduced NF- $\kappa \mathrm{B}$ nuclear translocation by $15 \%(p<0.05)$ and $9 \%(p>0.05)$ at 50 and $100 \mu \mathrm{g} \mathrm{mL}{ }^{-1}$, respectively (Fig. 5E). 
A

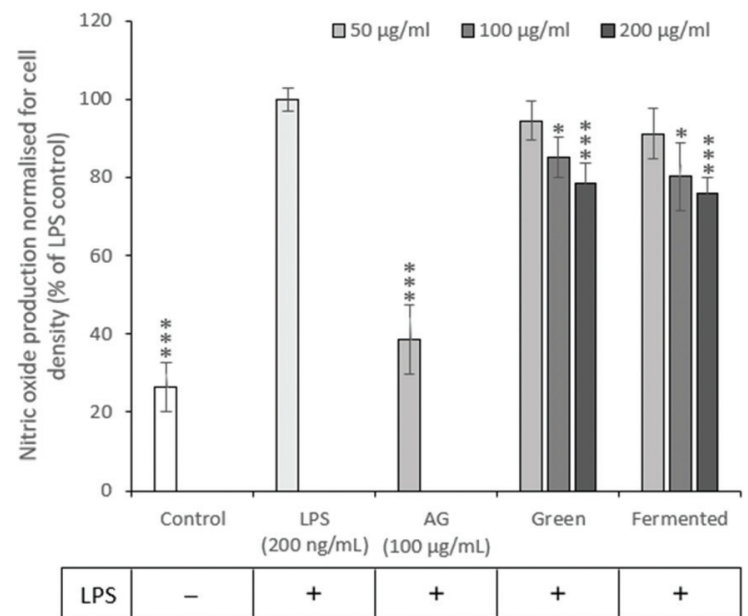

C

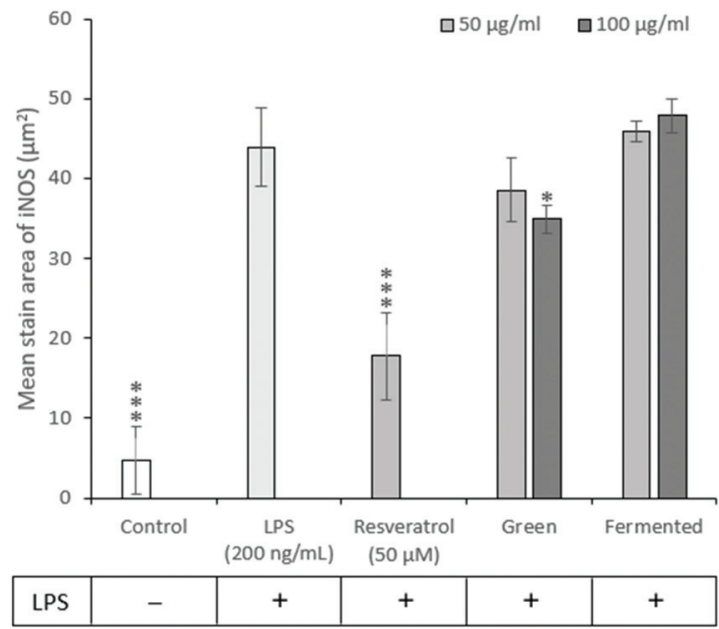

B

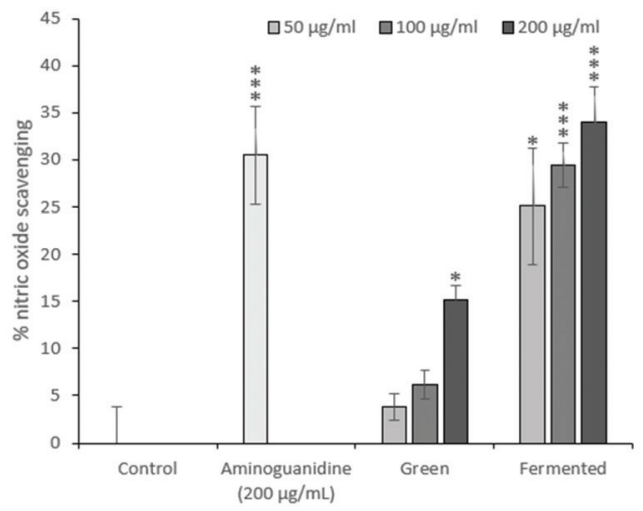

D

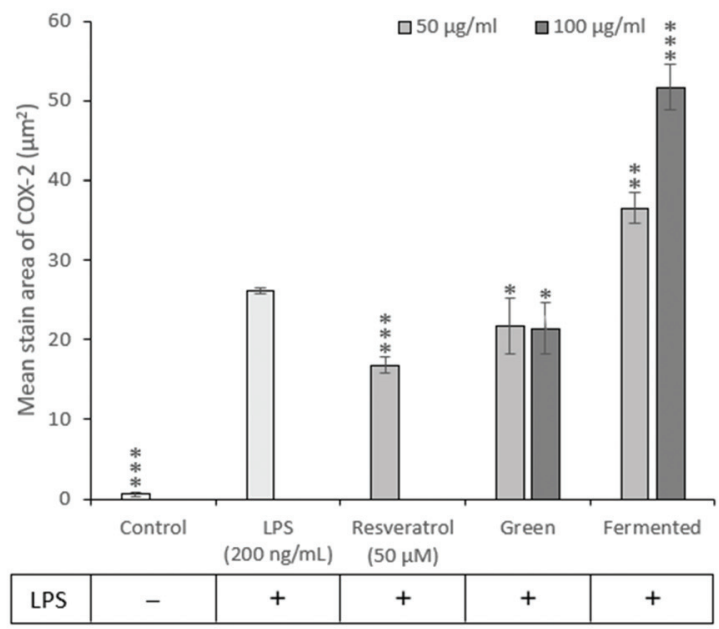

E

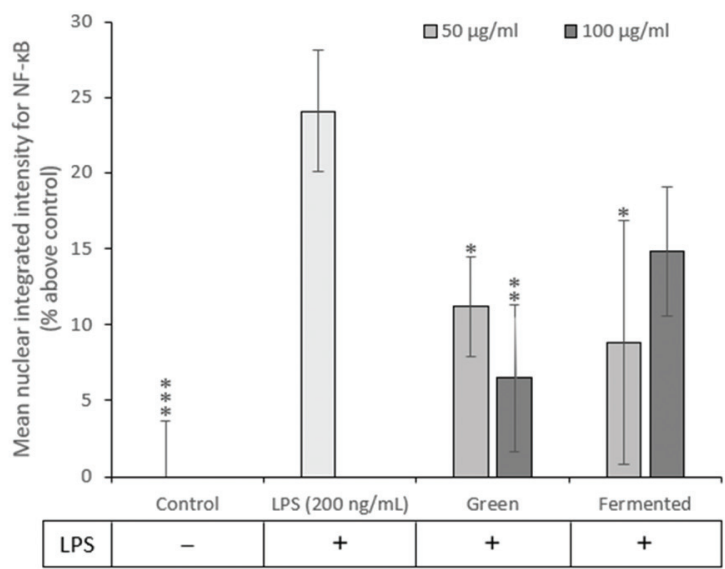

Fig. 5 Anti-inflammatory potential of $A$. linearis in LPS-activated RAW 264.7 cells comparing (A) the inhibition of NO production with (B) NO scavenging, (C) iNOS expression, (D) COX-2 and (E) NF- $\mathrm{kB}$ nuclear translocation. Aminoguanidine (AG) was included as a positive control for the inhibition and scavenging of NO, respectively, while resveratrol was included as a positive control for the expression of iNOS and COX-2. Data for NO production was normalised for cell density using the crystal violet assay. Results are reported as the mean \pm standard deviation (error bars shown in black) with all experiments performed three times, each in triplicate ( $T$-test: ${ }^{*} p<0.05 ;{ }^{* \star} p<0.01 ;{ }^{* *} p<0.005$ compared to LPS for A, C, D, E and compared to control for B). 
A previous study conducted by Mueller et $a l^{54}$ confirmed the effects of a fermented extract of $A$. linearis on iNOS and COX-2 levels in LPS-activated RAW 264.7 macrophages and further showed that this extract reduced the secretion of IL-6 and IL-10 but had no effect on TNF- $\alpha$. Due to the increase in COX-2 levels induced by fermented $A$. linearis, it is tempting to conclude that this is surely evidence of a pro-inflammatory response. It is important to remember, however, that COX-2 regulates the synthesis and secretion of both pro- and antiinflammatory prostaglandins and an increase in COX-2 could thus also be associated with an anti-inflammatory reaction. ${ }^{55}$ Further confirming the anti-inflammatory nature of $A$. linearis is the fact that several in vivo studies have documented its antiinflammatory potential. ${ }^{56,57}$ and others

Despite previous studies that have reported potentially proinflammatory effects such as increased NO levels in various cell models for $A$. linearis, particularly the fermented extract, to date no evidence confirming the pro-inflammatory nature of A. linearis during in vivo studies have been documented. ${ }^{58} \mathrm{~A}$ plausible explanation is that fermented A. linearis is likely to contain endotoxins which will induce a strong pro-inflammatory response in an in vitro setting, however, LPS is not bioavailable if taken orally thus eliminating such pro-inflammatory effects in the in vivo situation. The exceptional potency of LPS could override any anti-inflammatory effects in a cell culture experiment and thus mask its anti-inflammatory potential.

\subsection{Targeting pancreatic beta-cell function}

As diabetes progresses, $\beta$-cell function gradually declines resulting in $\beta$-cell exhaustion and eventual $\beta$-cell death characterised by a decrease in $\beta$-cell mass. ${ }^{59}$ Consequently, therapeutic strategies targeted towards promoting $\beta$-cell mass and function could provide unprecedented benefits during the treatment of both T1D and T2D. While much time and
A

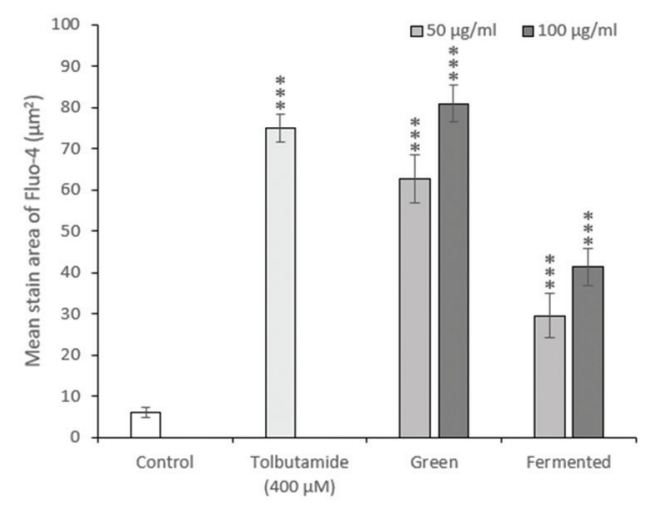

C

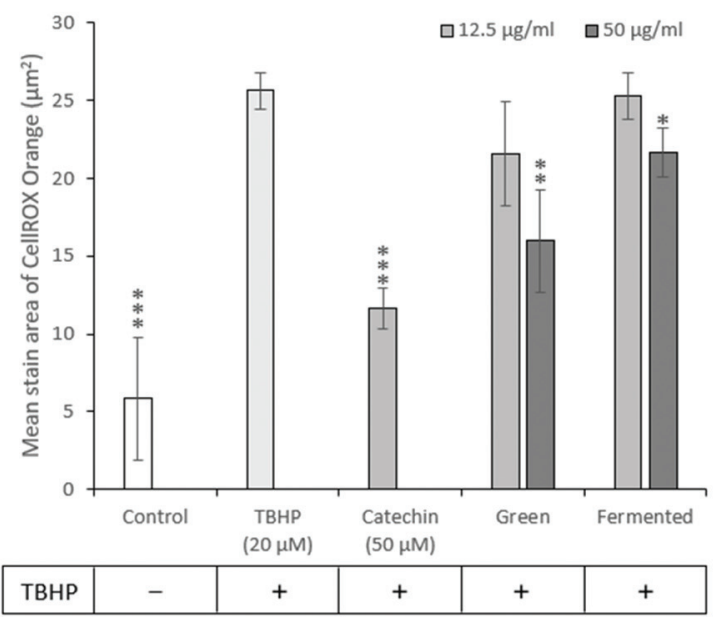

B

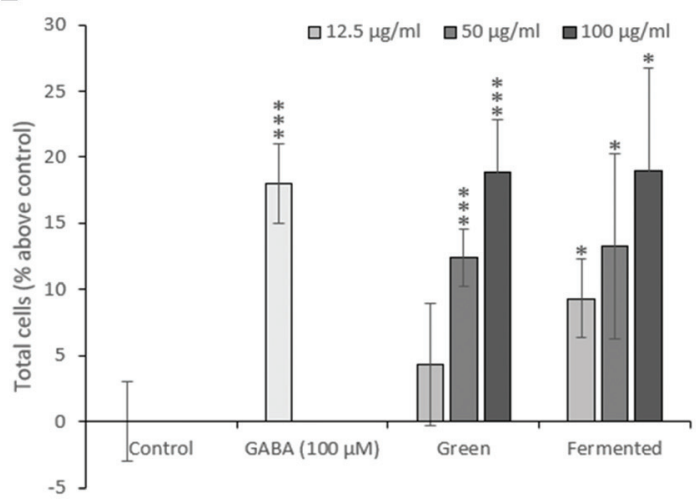

D

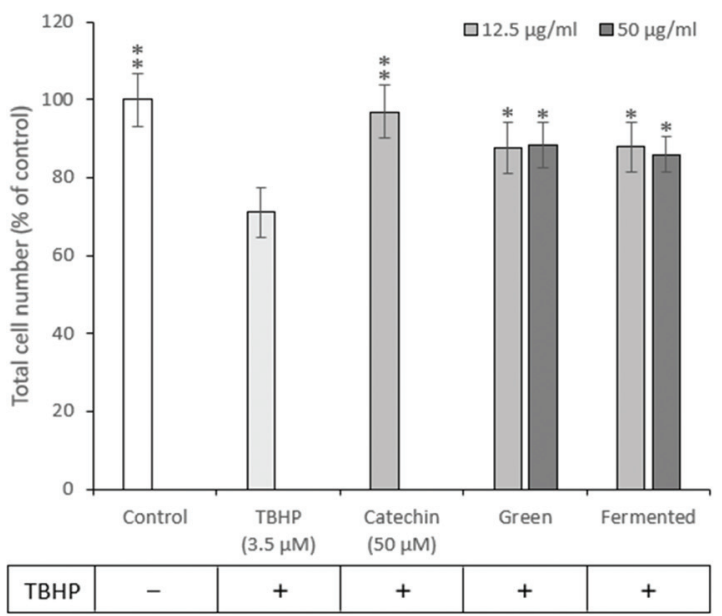

Fig. 6 Effect of $A$. linearis on INS-1 pancreatic $\beta$-cell function and survival comparing (A) intracellular calcium levels after a 10 minute treatment period in the absence of glucose with tolbutamide $(400 \mu \mathrm{M})$ included as a positive control for calcium influx; (B) $\beta$-cell proliferation after 24 hours using Hoechst 33342 staining of the nuclei with gamma-aminobutyric acid (GABA) included as a positive control; (C) intracellular ROS accumulation after being exposed to TBHP $(20 \mu \mathrm{M})$ for 2 hours using the CellROX Orange reagent; and (D) promotion of cell survival after 24 hours using TBHP $(3.5 \mu \mathrm{M})$ to promote oxidative stress-induced cell death. Results are reported as the mean \pm standard deviation (error bars shown in black) with all experiments performed three times, each in triplicate ( $T$-test: ${ }^{*} p<0.05 ;{ }^{* \star} p<0.01 ;{ }^{* \star *} p<0.005$ compared to control for A, B and compared to TBHP for C, D). 
research has been dedicated towards the development of treatment strategies targeting pancreatic $\beta$-cell mass, no such drugs are currently in clinical use. ${ }^{60}$ To this end, the ability of A. linearis to promote insulin secretion and proliferation while protecting $\beta$-cells against oxidative stress and apoptosis were investigated.

Because increased cellular levels of calcium stimulate the mobilisation of insulin granules to the plasma membrane and subsequent insulin secretion from pancreatic $\beta$-cells, cytosolic calcium levels are frequently used as an indirect measure of insulin secretion. ${ }^{61}$ Furthermore, the measurement of calcium levels appears more suitable for screening purposes than directly measuring insulin secreted into the medium with quantitative fluorescence microscopy being less time-consuming and more affordable than enzyme-linked immunosorbent assays (ELISA) or radioimmunoassays (RIA). ${ }^{62}$ Consequently, the ability of $A$. linearis green and fermented extracts to potentiate intracellular calcium levels and presumably stimulate insulin secretion was measured in INS-1 pancreatic $\beta$-cells where a higher measure of intracellular calcium level was presumed to be accompanied by a stronger propensity to stimulate insulin secretion as is known for tolbutamide. A. linearis green extract demonstrated the greatest ability to potentiate intracellular calcium levels and presumably insulin secretion in pancreatic $\beta$-cells in the absence of glucose, producing a stronger effect than the positive control tolbutamide $(400 \mu \mathrm{M})$ at an extract concentration of $100 \mu \mathrm{g} \mathrm{mL}^{-1}$ (Fig. 6A). While A. linearis fermented extract also demonstrated a highly promising ability to stimulate intracellular calcium flux $(p<0.005)$, this response was only equivalent to $50 \%$ of the effect of the green extract at the highest tested concentration of $100 \mu \mathrm{g}$ $\mathrm{mL}^{-1}$. A previous study documenting the effects of aspalathin, one of the major polyphenols isolated from A. linearis, on RIN-5F pancreatic $\beta$-cells concluded that this compound significantly stimulated insulin secretion at a concentration of $100 \mu \mathrm{M} .^{11}$ The increased activity of the green extract compared to the fermented extract on $\beta$-cell insulin secretion can thus be attributed to the increased presence of aspalathin. ${ }^{7}$

Due to the low antioxidative capacity of pancreatic $\beta$-cells and the propensity of diabetes to induce oxidative stress, the antioxidative potential of $A$. linearis was explored. Here it was found that the green extract of $A$. linearis presented the strongest antioxidative potential as this aspalathin-rich extract is specifically produced to contain a higher phenolic content and consequently higher antioxidant activity. ${ }^{63}$ This extract produced the lowest recorded Trolox equivalent (TE) value (0.87) and $\mathrm{EC}_{50}$ value $\left(4.92 \mu \mathrm{g} \mathrm{mL}^{-1}\right)$ during the FRAP and DPPH scavenging assays, respectively. The fermented extract demonstrated a slightly weaker but still rather promising antioxidative response (1.33 TE during FRAP; $\mathrm{EC}_{50}$ value of $7.33 \mu \mathrm{g}$ $\mathrm{mL}^{-1}$ during DPPH) due to the presence of fewer antioxidative compounds such as flavonoids and polyphenols as many of them are modified or destroyed during the fermentation process. ${ }^{23,64}$ These results are not surprising as the antioxidative potential of $A$. linearis has been well documented. ${ }^{65-67}$ and others Both the green and fermented extracts also demonstrated significant abilities to reduce TBHP-induced oxidative stress in INS-1 $\beta$-cells (Fig. 6C) at extract concentrations of $50 \mu \mathrm{g} \mathrm{mL}$ with the green extract once again producing a slightly stronger response.

T1D and T2D present very similar clinical symptoms prior to diagnosis yet they are defined by profoundly different aetiologies and underlying mechanisms. Nevertheless, both forms of this disease are ultimately characterised by a considerable reduction in $\beta$-cell mass and function. ${ }^{68}$ Therapeutic strategies targeted towards preserving and promoting $\beta$-cell mass could thus provide unparalleled advantages with regards to treating and potentially reversing diabetes altogether. To this end, the ability of $A$. linearis to promote $\beta$-cell mass by stimulating proliferation and/or promoting cell survival in the presence of oxidative-stress in INS-1 $\beta$-cells was investigated.

Both the green and fermented extracts of A. linearis exerted almost identical proliferation-stimulating abilities in INS-1 cells from $50 \mu \mathrm{g} \mathrm{mL} \mathrm{m}^{-1}$ (Fig. 6B). Surprisingly, both extracts also presented almost identical capacities to promote $\beta$-cell survival by attenuating the effects of TBHP on cell density by approximately $17 \%(p<0.05)$ at $12.5 \mu \mathrm{g} \mathrm{mL} \mathrm{m}^{-1}$ (Fig. 6D). This suggests that the effects of $A$. linearis on INS-1 $\beta$-cell mass are not dependent on the concentration of phenolic compounds present in these extracts and must therefore be attributed to the presence of some other compounds that are not affected by the fermentation process.

A previous study attributed several of the antidiabetic effects of A. linearis on a phytochemical called PPAG and showed that this compound could protect pancreatic $\beta$-cells in male Balb/c mice against the acute toxic effects of streptozotocin, glucotoxicity and oxidative stress. Furthermore, PPAG demonstrated both anti-apoptotic and anti-necrotic effects but

Table 1 Phenolic content (g per $100 \mathrm{~g}$ of extract) of the green and fermented extracts of $A$. linearis ${ }^{*}$

\begin{tabular}{|c|c|c|}
\hline Compounds & Green & Fermented \\
\hline$(S)$-Eriodictyol-6-C- $\beta$-D-glucopyranoside ${ }^{a}$ & nd & 1.03 \\
\hline$(R)$-Eriodictyol-6- $C$ - $\beta$-D-glucopyranoside ${ }^{a}$ & nd & 0.974 \\
\hline$(S)$-Eriodictyol-8-C- $\beta$-D-glucopyranoside ${ }^{a}$ & nd & 0.278 \\
\hline$(R)$-Eriodictyol-8-C- $\beta$-D-glucopyranoside ${ }^{a}$ & nd & 0.326 \\
\hline $\begin{array}{l}Z \text {-2-( } \beta \text {-D-glucopyranosyloxy)-3-phenylpropenoic } \\
\text { acid (PPAG) }\end{array}$ & 0.535 & 0.605 \\
\hline Aspalathin & 11.70 & 0.297 \\
\hline Nothofagin & 0.948 & 0.041 \\
\hline Iso-orientin & 1.037 & 0.886 \\
\hline Orientin & 1.187 & 1.128 \\
\hline Quercetin-3-O-robinobioside ${ }^{b}$ & 1.287 & 0.605 \\
\hline Vitexin & 0.193 & 0.195 \\
\hline Hyperoside & 0.419 & 0.129 \\
\hline Rutin & 0.554 & 0.117 \\
\hline Iso-vitexin and Isoquercitrin ${ }^{c}$ & 0.612 & 0.269 \\
\hline Luteolin-7-O- $\beta$-D-glucopyranoside & 0.036 & 0.041 \\
\hline
\end{tabular}

${ }^{a}$ Quantified in eriodictyol-7- $O-\beta$-D-glucopyranoside equivalents. ${ }^{b}$ Quantified in rutin equivalents. ${ }^{c}$ Sum of isovitexin and isoquercitrin in isovitexin equivalents. nd $=$ not detected. ${ }^{*}$ The extracts and the characterisation information were supplied by Prof Elizabeth Joubert and Prof Dalene de Beer from the Agricultural Research Council, South Africa. 
was not found to function as an antioxidant or protect cells against extensive DNA damage thus making it an interesting potential treatment strategy for the therapeutic or preventative application in diabetes/pre-diabetes. ${ }^{69}$ Examination of the phenolic content of the green and fermented extracts of A. linearis (Table 1) revealed that PPAG is indeed one of the few compounds present in both extracts in nearly equal concentrations $(0.535$ and $0.605 \mathrm{~g}$ per $100 \mathrm{~g}$ extract for the green and fermented extracts, respectively) with previous studies confirming that PPAG does not undergo degradation during the fermentation process. $^{23,64}$

\section{Conclusions}

In accordance with existing literature, both the green and fermented extracts of $A$. linearis demonstrated strong abilities to target multiple antidiabetic pathways, with the green extract often being superior and having a lower risk for toxicity than the fermented extract. Effective treatment concentrations represent pharmacologically relevant ranges of 100 to $500 \mu \mathrm{g}$ $\mathrm{mL}^{-1}$ in the intestine and 12.5 to $200 \mu \mathrm{g} \mathrm{mL} \mathrm{m}^{-1}$ for the remaining targets. The strong correlation to previously identified therapeutic mechanisms in various in vivo models, provides confidence as to the accuracy of the screening platform and the feasibility of this approach to characterise the antidiabetic capacity of medicinal plants. Moreover, significant effects on multiple independent therapeutic mechanisms clearly demonstrate the necessity to consider medicinal plants as multitarget therapeutics, a characteristic often overlooked in attempts to define the antidiabetic potential of medicinal plants including rooibos.

An important finding of the present study is the remarkable propensity for rooibos to target multiple facets regulating postprandial hyperglycaemia and the related secondary events which ensue in response to post meal glucose spiking. Proper glycaemic control is a major concern for diabetic patients with the postprandial state having a higher insulin requirement than the fasting state since blood glucose levels increase faster and more aggressively after meals. ${ }^{70}$ Furthermore, postprandial hyperglycaemia is recognised as a major contributory factor in the progression toward overt diabetes and is an independent risk factor for the development of atherosclerosis, a major diabetic complication. ${ }^{71,72}$ Subsequently, targeting post meal hyperglycaemia represents a therapeutic strategy with relevance to various facets of diabetes, ranging from early disease progression, poor glycaemic control at advanced stages, as well as complications associated with the disease.

With respect to postprandial hyperglycaemia, both rooibos extracts demonstrated rather promising abilities to delay carbohydrate digestion by inhibiting $\alpha$-glucosidase, the enzyme responsible for releasing glucose from dietary carbohydrates. Further, carbohydrate digestion controls incretin hormone activity and subsequent incretin induced insulin secretion. It is estimated that incretin hormones are responsible for a substantial portion of postprandial insulin release ${ }^{73}$ aiming to increase the disposal of blood glucose and restore glycaemic control. Inhibition of DPP-iv, an enzyme involved in incretin hormone degradation, displays significant postprandial glucose lowering effects. ${ }^{74}$ The capacity for rooibos to inhibit DPP-iv activity, albeit relatively weak, may therefore also contribute to alleviating postprandial hyperglycaemia by sustaining incretin hormone induced insulin release.

In contrast to the fasting state, postprandial glucose metabolism occurs predominantly via insulin sensitive pathways, placing pancreatic $\beta$-cell function as an essential component to counteract postprandial hyperglycaemia. ${ }^{75}$ Green rooibos, and to a lesser extent, fermented rooibos were found to strongly stimulate calcium-dependent insulin secretion in pancreatic $\beta$-cells, thereby providing an additional mechanism attributable to rooibos with the potential to mitigate postprandial hyperglycaemia.

Oxidative stress is a direct consequence of hyperglycaemia. Elevated blood glucose stimulates mitochondrial metabolism and as a result increases ROS production. ${ }^{76}$ Pancreatic $\beta$-cells are particularly sensitive to oxidative stress, ${ }^{77}$ therefore repeated hyperglycaemic insults leads to $\beta$-cell destruction and cumulative pancreatic dysfunction, both characteristics of diabetes. The strong antioxidant capacity of A. linearis effectively reduced ROS formation and promoted cell survival in INS-1 $\beta$-cells under conditions of severe oxidative stress. In addition, both green and fermented rooibos were strong activators of $\beta$-cell proliferation, raising the potential for rooibos to not only protect against post meal hyperglycaemia induced $\beta$-cell demise, but to also restore pancreatic function through neogenesis.

Poor glycaemic control is clinically diagnosed as elevated levels of glycated haemoglobin, ${ }^{78}$ indicating that in vivo advanced glycation end products are regarded a direct result of hyperglycaemia, including post meal glucose spiking. Protein glycation is a known causal factor for many diabetes related morbidities including chronic wounds, cardiovascular diseases and neuropathy. ${ }^{79}$ Rooibos was found to be a strong inhibitor of AGE formation which may dampen the negative impact of postprandial hyperglycaemia on the development of diabetes complications. In addition, activation of macrophages via AGE receptors (RAGE) promotes, through NF-kB signalling, a proinflammatory phenotype contributing to the inflammatory component of diabetes. ${ }^{80}$ Green rooibos was found to reduce NF-kB translocation in activated macrophages with a concomitant decline in NO production as well as the levels of the inflammatory markers; iNOS and COX-2.

Collectively, our data provides evidence to support the idea that the overall therapeutic potential of A. linearis represents a composite of many inter-related antidiabetic mechanisms with a strong tendency to attenuate postprandial hyperglycaemia and the subsequent metabolic dysfunction which arises as a result of poor glycaemic control. To the best of our knowledge no studies have been conducted to evaluate the effects of rooibos on postprandial hyperglycaemia in a diabetic animal model. 
Targeting postprandial hyperglycaemia is a well-established treatment strategy, however, treatment must coincide with the glycaemic load in order to be successful. One possible strategy to ensure this overlap would be to fortify high glycaemic foods with rooibos, provided the effective dosage does not impact on the sensory properties of such foods. Further studies should be focused on conducting well-designed in vivo experiments that may confirm the antidiabetic mechanisms of A. linearis proposed here.

\section{Conflicts of interest}

There are no conflicts to declare.

\section{Acknowledgements}

The authors express their gratitude to Profs. E. Joubert and D. de Beer from the Agricultural Research Council (Stellenbosch, South Africa) for the preparation and characterisation of the extracts as well as the CSIR through the African Laser Centre program and the HA Taylor Will Trust for their financial contribution towards this project. Furthermore, the financial assistance of the National Research Foundation (NRF) towards this research (PhD Scholarship, N. Pringle) is hereby acknowledged. Opinions expressed and conclusions arrived at, are those of the author and are not necessarily to be attributed to these organisations.

\section{Notes and references}

1 World Health Organization. Global Report on Diabetes, 2016.

2 A. Mohammed, M. A. Ibrahim and M. S. Islam, African medicinal plants with antidiabetic potentials: a review, Planta Med., 2014, 80(5), 354-377.

3 A. Alkhatib, C. Tsang, A. Tiss, T. Bahorun, H. Arefanian, R. Barake, A. Khadir and J. Tuomilehto, Functional Foods and Lifestyle Approaches for Diabetes Prevention and Management, Nutrients, 2017, 9(12), 1310.

4 M. S. Butt and M. T. Sultan, Selected Functional Foods for Potential in Disease Treatment and Their Regulatory Issues, Int. J. Food Prop., 2013, 16(2), 397-415.

5 I. Fraietta and F. Gasparri, The development of highcontent screening (HCS) technology and its importance to drug discovery, Expert Opin. Drug Discovery, 2016, 11(5), 501-514.

6 B.-E. Van Wyk, B. van Oudtshoorn and N. Gericke, Medicinal Plants of South Africa, Briza Publications, South Africa, 2nd edn, 2009.

7 R. Kamakura, M. J. Son, D. de Beer, E. Joubert, Y. Miura and K. Yagasaki, Antidiabetic effect of green rooibos (Aspalathus linearis) extract in cultured cells and type 2 diabetic model KK-Ay mice, Cytotechnology, 2015, 67(4), 699710.
8 N. Mikami, J. Tsujimura, A. Sato, A. Narasada, M. Shigeta, M. Kato, S. Hata and E. Hitome, Green rooibos extract from Aspalathus linearis, and its component, Aspalathin, suppress elevation of blood glucose levels in mice and inhibit $\alpha$-amylase and $\alpha$-glucosidase activities in vitro, Food Sci. Technol. Res., 2015, 21(2), 231-2410.

9 C. J. F. Muller, E. Joubert, D. de Beer, M. Sanderson, C. J. Malherbe, S. J. Fey and J. Louw, Acute assessment of an aspalathin-enriched green rooibos (Aspalathus linearis) extract with hypoglycemic potential, Phytomedicine, 2012, 20(1), 32-39.

10 P. Mose Larsen, S. J. Fey, J. Louw and L. Joubert, An antidiabetic extract of rooibos, European Patent No EP2120980B.1(WO2008/110551), 2008.

11 A. Kawano, H. Nakamura, S. Hata, M. Minakawa, Y. Miura and K. Yagasaki, Hypoglycemic effect of aspalathin, a rooibos tea component from Aspalathus linearis, in type 2 diabetic model $\mathrm{db} / \mathrm{db}$ mice, Phytomedicine, 2009, 16(5), 437-443.

12 C. J. F. Muller, E. Joubert, C. Pheiffer, S. Ghoor, M. Sanderson, N. Chellan, S. J. Fey and J. Louw, Z-2-( $\beta-D-$ glucopyranosyloxy)-3-phenylpropenoic acid, an $\alpha$-hydroxy acid from rooibos (Aspalathus linearis) with hypoglycemic activity, Mol. Nutr. Food Res., 2013, 57(12), 2216-2222.

13 S. E. Mazibuko-Mbeje, P. V. Dludla, C. Roux, R. Johnson, S. Ghoor, E. Joubert, J. Louw, A. R. Opoku and C. J. F. Muller, Aspalathin-enriched green rooibos extract reduces hepatic insulin resistance by modulating PI3 K/ AKT and AMPK pathways, Int. J. Mol. Sci., 2019, 20(3), 633.

14 S. E. Mazibuko, E. Joubert, R. Johnson, J. Louw, A. R. Opoku and C. J. Muller, Aspalathin improves glucose and lipid metabolism in 3T3-L1 adipocytes exposed to palmitate, Mol. Nutr. Food Res., 2015, 59, 2199-2208.

15 E. M. Lee, S. S. Lee, B. Y. Chung, J. Y. Cho, I. C. Lee, S. R. Ahn, S. J. Jang and T. H. Kim, Pancreatic lipase inhibition by C-glycosidic flavones Isolated from Eremochloa ophiuroides, Molecules, 2010, 15(11), 8251-5289.

16 M. Sanderson, S. E. Mazibuko, E. Joubert, D. de Beer, R. Johnson, C. Pheiffer, J. Louw and C. J. Muller, Effects of fermented rooibos (Aspalathus linearis) on adipocyte differentiation, Phytomedicine, 2014, 21(2), 109-117.

17 C. Smith and A. C. Swart, Rooibos (Aspalathus linearis) facilitates an anti-inflammatory state, modulating IL-6 and IL-10 while not inhibiting the acute glucocorticoid response to a mild novel stressor in vivo, J. Funct. Foods, 2016, 27, 42-54.

18 S. Yang, C. Lee, B.-S. Lee, E. K. Park, K.-M. Kim and J.-S. Bae, Renal protective effects of aspalathin and nothofagin from rooibos (Aspalathus linearis) in a mouse model of sepsis, Pharmacol. Rep., 2018, 70(6), 1195-1201.

19 W. Lee and J.-S. Bae, Anti-inflammatory Effects of Aspalathin and Nothofagin from Rooibos (Aspalathus linearis) In Vitro and In Vivo, Inflammation, 2015, 38(4), 1502-1516.

20 W. Lee, K.-M. Kim and J.-S. Bae, Ameliorative Effect of Aspalathin and Nothofagin from Rooibos (Aspalathus linearis) on HMGB1-Induced Septic Responses In Vitro and In Vivo, Am. J. Chin. Med., 2015, 43(5), 991-1012. 
21 S.-K. Ku, S. Kwak, Y. Kim and J.-S. Bae, Aspalathin and Nothofagin from Rooibos (Aspalathus linearis) inhibits high glucose-induced inflammation in vitro and in vivo, Inflammation, 2015, 38(1), 445-455.

22 E. Joubert and D. De Beer, Phenolic content and antioxidant activity of rooibos food ingredient extracts, J. Food Compos. Anal., 2012, 27, 45-51.

23 N. A. Walters, A. De Villiers, E. Joubert and D. De Beer, Improved HPLC method for rooibos phenolics targeting changes due to fermentation, J. Food Compos. Anal., 2017, 55, 20-29.

24 Z. Xiao, R. Storms and A. Tsang, A quantitative starchiodine method for measuring alpha-amylase and glucoamylase activities, Anal. Biochem., 2006, 351(1), 146148.

25 O. A. Akinloye, E. A. Balogun, S. O. Kareem and O. S. Mosaku, Partial purification and some properties of $\alpha$-glucosidase from Trichoderma longibrachiatum, Biokemistri, 2012, 24(1), 31-37.

26 N. Matsuura, T. Aradate, C. Sasaki, H. Kojima, M. Ohara, J. Hasegawa and M. Ubukata, Screening system for the Maillard reaction inhibitor from natural product extracts, J. Health Sci., 2002, 48, 520-526.

27 J. A. Lott and K. Turner, Evaluation of Trinder's glucose oxidase method for measuring glucose in serum and urine, Clin. Chem., 1975, 21(12), 1754-1760.

28 G. R. de Abreu Cabral, Z. T. Wang, L. D. Sibley and R. A. DaMatta, Inhibition of nitric oxide production in activated macrophages caused by Toxoplasma gondii infection occurs by distinct mechanisms in different mouse macrophage cell lines, Front. Microbiol., 2018, 9, 1936.

29 N. Balakrishnan, A. B. Panda, N. R. Raj, A. Shrivastava and R. Prathani, The evaluation of nitric oxide scavenging activity of Acalypha indica linn root, Asian J. Res. Chem., 2009, 2(2), 148-150.

30 G. J. Boukes and M. van de Venter, Rooperol as an antioxidant and its role in the innate immune system: An in vitro study, J. Ethnopharmacol., 2012, 144, 692699.

31 S. McKillup, Statistics explained: an introductory guide for life scientists, Cambridge University Press, United Kingdom, 2nd edn, 2012, pp. 44-55.

32 E. Joubert, W. C. A. Gelderblom, A. Louw and D. de Beer, South African herbal teas: Aspalathus linearis, Cyclopia spp. and Athrixia phylicoides-a review, J. Ethnopharmacol., 2008, 119(3), 376-412.

33 Z. Hübsch, S. F. van Vuuren and R. L. van Zyl, Can rooibos (Aspalathus linearis) tea have an effect on conventional antimicrobial therapies?, S. Afr. J. Bot., 2014, 93, 148156.

34 J. L. Marnewick, F. Rautenbach, I. Venter, H. Neethling, D. M. Blackhurst, P. Wolmarans and M. Macharia, Effects of rooibos (Aspalathus linearis) on oxidative stress and biochemical parameters in adults at risk for cardiovascular disease, J. Ethnopharmacol., 2011, 133(1), 46-52.
35 D. Giugliano, A. Ceruello and K. Esposito, Glucose metabolism and hyperglycemia, Am. J. Clin. Nutr., 2008, 87(1), 217S-222S.

36 B. E. Goodman, Insights into digestion and absorption of major nutrients in humans, Adv. Physiol. Educ., 2010, 34(2), 44-53.

37 R. Tundis, M. R. Loizzo and F. Menichini, Natural products as alpha-amylase and alpha-glucosidase inhibitors and their hypoglycaemic potential in the treatment of diabetes: an update, Mini-Rev. Med. Chem., 2010, 10(4), 315-331.

38 A. Vella, Mechanism of action of DPP-4 inhibitors-New insights, J. Clin. Endocrinol. Metab., 2012, 97(8), 2626-2628.

39 B. Kim, H. Y. Kim, I. Choi, J. Kim, C. H. Jin and A. Han, DPP-IV Inhibitory Potentials of Flavonol Glycosides Isolated from the Seeds of Lens culinaris: In Vitro and Molecular Docking Analyses, Molecules, 2018, 23(8), 1998.

40 D. C. Pinto-Junior, K. S. Silva, M. L. Michalani, C. Y. Yonamine, J. V. Esteves, N. T. Fabre, K. Thieme, S. Catanozi, M. M. Okamoto, P. M. Seraphim, M. L. CorrêaGiannella, M. Passarelli and U. F. Machado, Advanced glycation end products induced insulin resistance involves repression of skeletal muscle GLUT4 expression, Sci. Rep., 2018, 8, 8109.

41 H. Unoki, H. Bujo, S. Yamagishi, M. Takeuchi, T. Imaizumi and Y. Saito, Advanced glycation end products attenuate cellular insulin sensitivity by increasing the generation of intracellular reactive oxygen species in adipocytes, Diabetes Res. Clin. Pract., 2007, 76(2), 236-244.

42 C. H. Wu, H. W. Huang, S. M. Huang, J. A. Lin, C. T. Yeh and G. C. Yen, AGE-induced interference of glucose uptake and transport as a possible cause of insulin resistance in adipocytes, J. Agric. Food Chem., 2011, 59(14), 7978-7984.

$43 \mathrm{H}$. Vlassara and J. Uribarri, Advanced glycation end products (AGE) and diabetes: Cause, effect, or both?, Curr. Diabetes Rep., 2015, 14(1), 453.

44 N. Kinae, K. Shimoi, S. Masumori, M. Harusawa and M. Furugori, Suppression of the formation of advanced glycosylation products by tea extracts, Food Phytochemicals for Cancer Prevention II, 1994, pp. 68-75.

45 O. Ulicná, O. Vancová, P. Bozek, J. Cársky, K. Sebeková, P. Boor, M. Nakano and M. Greksák, Rooibos tea (Aspalathus linearis) partially prevents oxidative stress in streptozotocin-induced diabetic rats, Physiol. Res., 2006, 55(2), 157-164.

46 S. P. Sah, B. Singh, S. Choudhary and A. Kumar, Animal models of insulin resistance: A review, Pharmacol. Rep., 2016, 68(6), 1165-1177.

47 R. Beltán-Debón, A. Rull, F. Rodriguez-Sanabria, I. Iswaldi, M. Herranz-López, G. Aragonès, J. Camps, C. AlonsoVillaverde, J. A. Menéndez, V. Micol, A. Segura-Carretero and J. Jovan, Continuous administration of polyphenols from aqueous rooibos (Aspalathus linearis) extract ameliorates dietary-induced metabolic disturbances in hyperlipidemic mice, Phytomedicine, 2011, 18(5), 414-424. 
48 S. E. Mazibuko, C. J. Muller, E. Joubert, D. de Beer, R. Johnson, A. R. Opoku and J. Louw, Amelioration of palmitate-induced insulin resistance in C2C12 muscle cells by rooibos (Aspalathus linearis), Phytomedicine, 2013, 20(10), 813-819.

49 J. Tanti, F. Ceppo, J. Jager and F. Berthou, Implication of inflammatory signaling pathways in obesity-induced insulin resistance, Front. Endocrinol., 2013, 3, 181.

50 A. B. Goldfine, V. Fonseca, K. A. Jablonski, Y. D. Chen, L. Tipton, M. A. Staten and S. E. Shoelson, (2013) Salicylate (salsalate) in patients with type 2 diabetes: a randomized trial, Ann. Intern. Med., 2013, 159(1), 1-12.

51 P. N. Bellucci, M. F. G. Bagnes, G. D. Girolamo and C. D. Gonzalez, Potential Effects of Nonsteroidal AntiInflammatory Drugs in the Prevention and Treatment of Type 2 Diabetes Mellitus, J. Pharm. Pract., 2017, 30(5), 549556.

52 B. E. Sansbury and B. G. Hill, Regulation of obesity and insulin resistance by nitric oxide, Free Radical Biol. Med., 2014, 73, 383-399.

53 A. Jankovic, A. Korac, B. Buzadzic, A. Stancic, V. Otasevic, P. Ferdinandy, A. Daiber and B. Korac, Targeting the NO/ superoxide ratio in adipose tissue: relevance to obesity and diabetes management, Br. J. Pharmacol., 2017, 174(12), 1570-1590.

54 M. Mueller, S. Hobiger and A. Jungbauer, Anti-inflammatory activity of extracts from fruits, herbs and spices, Food Chem., 2010, 122(4), 987-996.

55 B. Poligone and A. S. Baldwin, Positive and Negative Regulation of NF-kB by COX-2, J. Biol. Chem., 2001, 274(42), 38658-38664.

56 H. Baba, Y. Ohtsuka, H. Haruna, T. Lee, S. Nagata, M. Maeda, Y. Yamashiro and T. Shimizu, Studies of antiinflammatory effects of rooibos tea in rats, Pediatr. Int., 2009, 51, 700-704.

57 O. R. Ajuwon, O. O. Oguntibju and J. L. Marnewick, Amelioration of lipopolysaccharide-induced liver injury by aqueous rooibos (Aspalathus linearis) extract via inhibition of pro-inflammatory cytokines and oxidative stress, $B M C$ Complementary Altern. Med., 2014, 14, 392.

58 M. Hoosen, The effects of Aspalathus linearis, (Rooibos tea) on nitric oxide (NO) and cytokine activity, Int. J. Hum. Health Sci., 2019, 3(3), 150-157.

59 M. E. Cerf, Beta Cell Dysfunction and Insulin Resistance, Front. Endocrinol., 2013, 4, 37.

60 C. Chen, C. M. Cohrs, J. Stertmann, R. Bozsak and S. Speier, Human beta cell mass and function in diabetes: Recent advances in knowledge and technologies to understand disease pathogenesis, Mol. Metab., 2017, 6(9), 943957.

61 J. H. R. Kenty and D. A. Melton, Testing Pancreatic Islet Function at the Single Cell Level by Calcium Influx with Associated Marker Expression, PLoS One, 2015, 10(4), e0122044.

62 V. Ljosa and A. E. Carpenter, Introduction to the Quantitative Analysis of Two-Dimensional Fluorescence
Microscopy Images for Cell-Based Screening, PLoS Comput. Biol., 2009, 5(12), e1000603.

63 E. Joubert and D. de Beer, Rooibos (Aspalathus linearis) beyond the farm gate: From herbal tea to potential phytopharmaceutical, S. Afr. J. Bot., 2011, 77(4), 869886.

64 D. de Beer, J. Tobin, B. Walczak, M. van der Rijst and E. Joubert, Phenolic composition of rooibos changes during simulated fermentation: Effect of endogenous enzymes and fermentation temperature on reaction kinetics, Food Res. Int., 2019, 121, 185-196.

65 J. L. Marnewick, Antioxidant Properties of Rooibos (Aspalathus linearis) - In Vitro and in Vivo Evidence, in Systems Biology of Free Radicals and Antioxidants. ed. I. Laher, Springer, Germany, 2014.

66 O. R. Ajuwon, J. L. Marnewick and L. M. Davids, Rooibos (Aspalathus linearis) and its major flavonoids - potential against oxidative stress-induced conditions, in Basic Principles and Clinical Significance of Oxidative Stress. ed. S. J. T. Gowder. IntechOpen, Croatia, 2015.

67 S. Suna, Investigating the physicochemical properties and in vitro bioaccessibility of phenolics and antioxidant capacity of rooibos herbal tea beverage, Gida, 2017, 42(6), 682-692.

68 D. Pipeleers, M. Chintinne, B. Denys, G. Martens, B. Keymeulen and F. Gorus, Restoring a functional betacell mass in diabetes. Diabetes, Obes. Metab., 2008, 10(4), 54-62.

69 E. Himpe, D. A. Cunha, I. Song, M. Bugliani, P. Marchetti, M. Cnop and L. Bouwens, Phenylpropenoic acid glucoside from rooibos protects pancreatic beta cells against cell death induced by acute injury, PLoS One, 2016, 11(6), e0157604.

70 D. U. Silverthorn, Human Physiology: An Integrated Approach, Pearson, England, 6th edn, 2014, pp. 796-801.

71 M. Hanefeld and T. Temelkova-Kurktschiev, The postprandial state and the risk of atherosclerosis, Diabetic Med., 1997, 14(S3), S6-S11.

72 A. Ceriello, Postprandial hyperglycemia and diabetes complications: is it time to treat?, Diabetes, 2005, 54(1), $1-7$.

73 M. Nicolaus, J. Brödl, R. Linke, H.-J. Woerle, B. Göke and J. Schirra, Endogenous GLP-1 Regulates Postprandial Glycemia in Humans: Relative Contributions of Insulin, Glucagon, and Gastric Emptying, J. Clin. Endocrinol. Metab., 2011, 96(1), 229-236.

74 J. Gerich, Pathogenesis and management of postprandial hyperglycemia: role of incretin-based therapies, Int. J. Gen. Med., 2013, 6, 877-895.

75 S. L. Aronoff, K. Berkowitz, B. Shreiner and L. Want, Glucose Metabolism and Regulation: Beyond Insulin and Glucagon, Diabetes Spectr., 2004, 17(3), 183-190.

76 G. L. King and M. R. Loeken, Hyperglycemia-induced oxidative stress in diabetic complications, Histochem. Cell Biol., 2004, 122(4), 333-338. 
77 P. A. Gerber and G. A. Rutter, The Role of Oxidative Stress and Hypoxia in Pancreatic Beta-Cell Dysfunction in Diabetes Mellitus, Antioxid. Redox Sign., 2017, 26(10), 501518.

78 American Diabetes Association, Diagnosis and Classification of Diabetes Mellitus, Diabetes Care, 2014, 37(Supplement 1), S81-S90.
79 V. P. Singh, A. Bali, N. Singh and A. S. Jaggi, Advanced glycation end products and diabetic complications, Korean J. Physiol. Pharmacol., 2014, 18(1), 1-14.

80 X. Jin, T. Yao, Z. Zhou, J. Zhu, S. Zhang, W. Hu and C. Shen, Advanced Glycation End Products Enhance Macrophages Polarization into M1 Phenotype through Activating RAGE/ NF- $\kappa$ B Pathway, BioMed Res. Int., 2015, 732450. 